\title{
Calculated and Measured Depth Dose Profiles in a Phantom Exposed to Neutron Radiation Fields
}
R. I. Scherpelz
J. E. Tanner
L. A. Sigalla
D. E. Hadlock

May 1989

Prepared for the

U.S. Department of Energy

Assistant Secretary for

Environment, Safety, and Health

under Contract DE-AC06-76RLO 1830

Pacific Northwest Laboratory

Operated for the U.S. Department of Energy

by Battelle Memorial Institute 


\title{
DISCLAIMER
}

This program was prepared as an account of work sponsored by an agency of the United States Government. Neither the United States Government nor any agency thereof, nor Battelie Memorial Institute, nor any of their employees, makes any warranty, express or implied, or assumes any legal liability or responsibility for the accuracy, completeness, or usefulness of any information, apparatus, product, or process disclosed, or represents that its use would not infringe privately omed rights. Reference herein to any specific commerical product, process, or service by trade name, trademark, manufacturer, or otherwise, does not necessarily constitute or imply its endorsement, recommendation, or favoring by the United States Government or any agency thereof, or Battelle Memorial Institute. The views and opinions of authors expressed herein do not necessarily state or reflect those of the United States Government or any agency thereof.

\section{PACIFIC NORTHWEST LABORATORY operated by \\ BATTELLE MEMORIAL INSTITUTE \\ for the \\ UNITED STATES DEPARTMENT OF ENERGY \\ under Contract DE-ACO6-76RLO 1830}

\author{
Printed in the United States of America \\ Available from \\ National Technical Information Service \\ United States Department of Commerce \\ 5285 Pon Royal Road \\ Springfield, Virginia 22161 \\ NTIS Price Codes \\ Microfiche ADT \\ Printed Copy
}

$\begin{array}{cc}\text { Pages } & \begin{array}{c}\text { Price } \\ \text { Codes }\end{array} \\ 001-025 & \text { A02 } \\ 026-050 & \text { A03 } \\ 051-075 & \text { A04 } \\ 076-100 & \text { A05 } \\ 101-125 & \text { A06 } \\ 126-150 & \text { A07 } \\ 151-175 & \text { A0B } \\ 176-200 & \text { A09 } \\ 201-225 & \text { A10 } \\ 226-250 & \text { A11 } \\ 251-275 & \text { A12 } \\ 276-300 & \text { A13 }\end{array}$


R. I. Scherpelz

J. E. Tanner

L. A. Sigalla(a)

D. E. Hadlock

May 1989

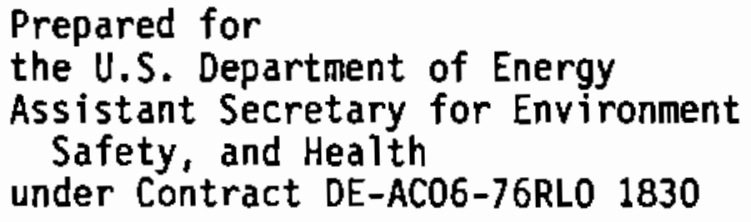

Pacific Northwest Laboratory

Richland, Washington 99352

(a) University of Washington Seattle, Washington 


\section{SUMMARY}

An accurate evaluation of doses caused by external sources of neutron radiation depends on knowledge of the transport of radiation inside the human body. Health physicists use two primary methods for studying this radiation transport: computer calculations and measurements. In a study requested by the U.S. Department of Energy and conducted by Pacific Northwest Laboratory, both computer calculations and measurements were performed under well controlled, nearly identical conditions in order to determine the extent of their agreement. A comparison of the dose profiles predicted by both measurements and calculations was thus possible.

The measurements were performed in a cylindrical phantom made of tissue equivalent plastic. The phantom size, $61 \mathrm{~cm}$ high and $30 \mathrm{~cm}$ in diameter, was chosen to approximate the human torso and to match the dimensions of cylindrical phantoms used by previous calculations. Holes were drilled down through the phantom to accomodate small tissue equivalent proportional counters (TEPCS) at various depths in the phantom. These counters were used to measure the neutron dose inside the phantom when it was exposed to various sources of neutrons. The holes in the phantom could also accommodate miniature Geiger-Mueller detectors to measure the gamma component of the dose. Neutron and ganma dose profiles were measured for two different sources of neutrons: an unmoderated $252 \mathrm{cf}$ source and a $733-\mathrm{keV}$ neutron beam generated by a Van de Graaff accelerator.

The depth dose calculations were performed using the computer code MCNP, a coupled neutron-photon transport code based on the Monte Carlo technique. MCNP runs were performed for both neutron sources, modeling the cylindrical phantom loaded with detectors in configurations that matched the experimental conditions. The radiation sources used in the calculations were designed to match the physical sources in both energy distribution and directionality.

The agreement between the calculated and measured depth dose profiles was excellent for cases where the experimental conditions could be accurately modeled in the calculations. For the bare $252 \mathrm{Cf}$ source, the agreement between measured and calculated depth dose profiles was excellent. For the 733-keV neutron beam from the Van de Graaff accelerator, the comparison was 
fairly good, limited primarily by poor counting statistics in the measurements. For nearly all data points there was overlap between the error bars for the measurement and corresponding calculation.

The study demonstrated a basic agreement between the radiation transport calculations and the in-phantom measurement techniques. Where the counting conditions were favorable and could be well represented in calculations, the two techniques gave the same results. Poorer agreements resulted when the experimental conditions could not be exactly modeled in the calculations.

This comparison study exhibits the relative strengths and weaknesses of calculations and measurements. Measurements must be the primary means of study in cases where the experimental conditions cannot be exactly modeled in calculations. Computer models, however, can be used in many situations where experimental measurements cannot be performed. The good agreement between measurements and calculations found in this study should give the health physicist confidence in using either calculations or measurements for determining depth dose profiles in a phantom. 


\section{ACKNOWLEDGMENTS}

The work reported in this document was sponsored by the U.S. Department of Energy's Office of Safety. Policy, and Standards. We appreciate the support provided by DOE for this research effort.

The authors have appreciated the opportunity to work with Bob Schwartz of the National Bureau of Standards and Marvin Lien and others at the PNL Van de Graaff accelerator. They provided more than just neutrons in support of this study.

Production of this report was made possible with the word processing expertise of Marianna Cross, the technical editing of Jim Weber, and technical review by Jim Durham. Thanks to all of them. 


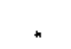




\section{CONTENTS}

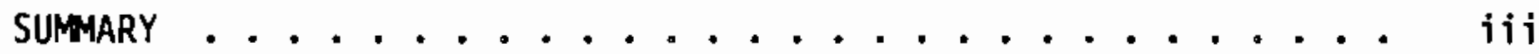

ACKNOWLEDGMENTS .................... v

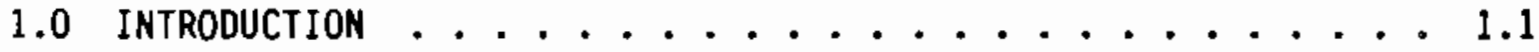

2.0 MeASUREMENT TECHNIQUE $\ldots \ldots \ldots \ldots \ldots$

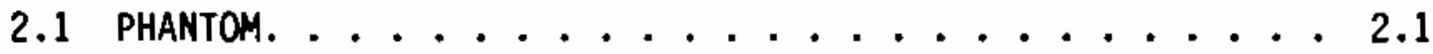

2.2 TEPC AND ElECTRONICS . . . . . . . . . . . 2.4

2.2.1 Description of TEPC Detector . . . . . . 2.5

2.2.2 TEPC Data Analysis ... . . . . . . 2.7

2.2.3 TEPC Uncertainties . . . . . . . . . 2.8

2.3 GM COUNTER AND ELECTRONICS . . . . . . . . . 2.9

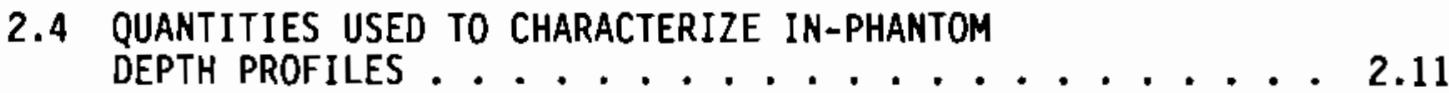

3.0 Calculation teChN1QUE . . . . . . . . . . 3.1

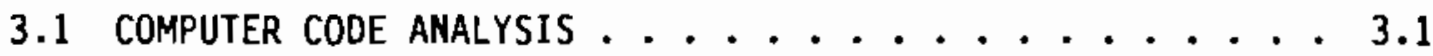

3.1.1 Monte Carlo Neutron and Photon Transport Code . . 3.1

3.1 .2 Cross-Section Libraries . . . . . . . . 3.2

3.1.3 VAX, HP-9000 Computer Environments . . . . 3.2

3.2 CALCULATION MODEL $\ldots \ldots \ldots \ldots . \ldots . \ldots . \ldots$

4.0 DEPTH DOSE PROFILES RESULTING FROM 252Cf IRRADIATION . . . . 4.1

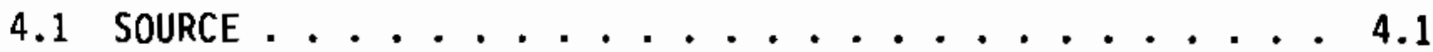

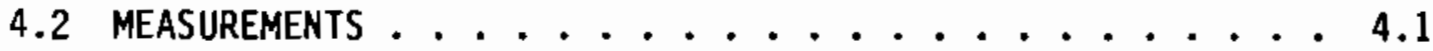

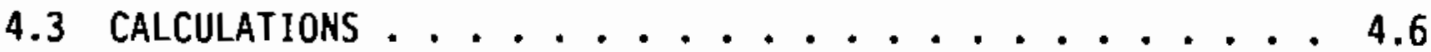

4.4 COMPARISON OF MEASUREMENTS AND CALCULATIONS $\ldots \ldots . . .4 .9$

5.0 DEPTH DOSE PROFILES RESULTING FROM 733-keV NEUTRONS . . . 5.1

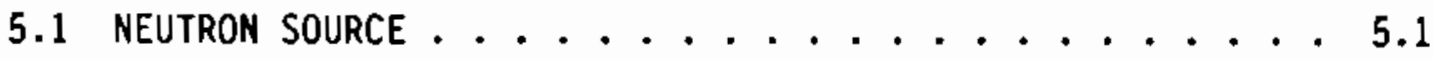




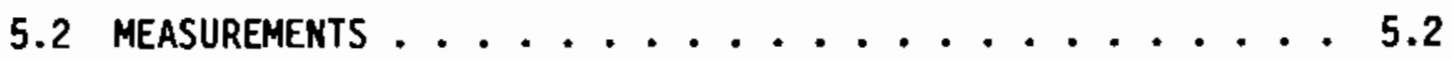

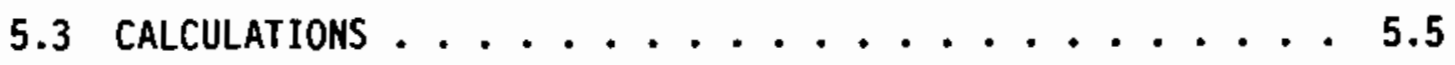

5.4 COMPARISON OF MEASUREMENTS AND CALCULATIONS $\ldots \ldots .$.

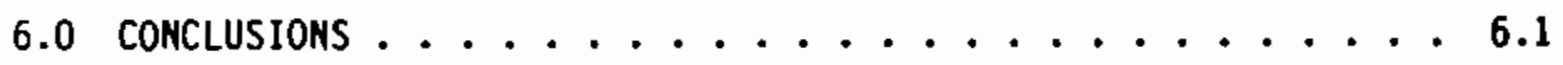

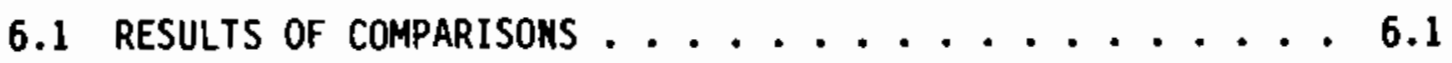

6.2 SIGNIFICANCE TO HEALTH PHYSICS APPLICATIONS $\ldots \ldots . .6 .2$

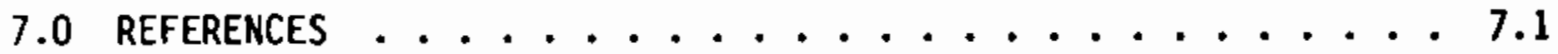




\section{FIGURES}

2.1 Phantom and TEPC Detector .............. 2.3

2.2 Detector Positions in Phantom ............. 2.4

2.3 Phantom and Electronic Components ............ 2.6

3.1 Neutron Flux Profile in Phantom . . . . . . . . 3.6

3.2 Neutron Dose Rate Profile in Phantom . . . . . . . 3.7

4.1 Exposure of Phantom to 252cf Source . . . . . . . . 4.2

4.2 Measured Dose Rates from $252 \mathrm{Cf} \ldots \ldots . . . \ldots . . . . . .4 .5$

4.3 Calculated Dose Rates from 252cf ............ 4.8

4.4 Comparison of Dose Rates from 252Cf . . . . . . . . 4.9

5.1 Experimental Configuration for Van de Graaff Accelerator with 733-kev Beam ........... 5.2

5.2 Measured Doses from 733-keV Neutrons . . . . . . . 5.5

5.3 Calculated Doses from 733-keV Neutrons . . . . . . 5.8

5.4 Comparison of Doses from 733-keV Neutrons . . . . . . 5.9 


\section{TABLES}

2.1 Elemental Composition of Tissue Equivalent Plastic and Propane-Based Tissue Equivalent Gas . . . . . . . . . 2.2

3.1 Caiculated Fluxes in a Homogeneous Phantom and in a Phantom Containing Detectors . . . . . . . . . . 3.5

4.1 Measured Neutron Dose Rates in a Phantom Exposed to Neutrons from an Unmoderated $252 \mathrm{Cf}$ Source . . . . . . . 4.3

4.2 Photon Dose Rate Measurements in a Phanton Exposed to Neutrons from 252Cf Source . . . . . . . . . . . 4.4

4.3 Energy Grouping of Radiation Emitted by $252 \mathrm{Cf}$. . . . . . . 4.6

4.4 Calculated Photon Dose Rates from 252Cf . . . . . . . . 4.7

4.5 Calculated Neutron and Photon Dose Rates from 252 Cf . . . . . 4.7

5.1 Distribution of Neutron Energies over Phantom Face . . . . . 5.3

5.2 Measured Neutron Doses in a Phantom Exposed to 733-keV Neutrons ................ 5.4

5.3 Measured Photon Doses in a Phanton Exposed to 733-keV Neutrons ............... 5.4

5.4 Calculated Flux and Dose Distributions in a Phanton Exposed to 733-keV Neutrons ................ 


\subsection{INTRODUCTION}

The evaluation of external radiation dose to a person usually involves determining the radiation field at the outside surface of the body, then applying an appropriate conversion factor to convert this value to dose or dose equivalent. The conversion factor must be derived from depth dose profiles in a phantom. Health physicists can evaluate depth dose profiles using either in-phantom measurements or calculations. Calculations are generally relied on for producing most of the data sets used in actual practice, but in-phantom measurements offer an aiternative approach. Since both approaches are important tools for determining depth dose profiles, it is important to understand how well they can be expected to agree with each other.

In a study conducted by Pacific Northwest Laboratory (PNL) (a) at the request of the U.S. Department of Energy, both measurements and calculations were used to evaluate dose profiles inside a phantom exposed to various sources of neutrons.

External dosimetry has an inherent difficulty of predicting biological effects inside a subject's body when the radiation field is actually determined outside the body. It is usually impossible to characterize the radiation field in sufficient detail inside the body where the important effects occur. As a typical example, a radiation detector located in free space would evaluate the radiation field in terms of flux as a function of energy, then use energy-dependent fluence-to-dose-equivalent conversion factors to evaluate the dose equivalent rate that a person would be expected to receive from the radiation field at that location. The set of fluence-to-doseequivalent conversion factors used in a routine application is often overlooked or taken for granted, but the assumptions used in developing the data set are very important in the ultimate value of dose equivalent that is assigned.

(a) Operated by Battelle Memorial Institute for the U.S. Department of Energy under Contract DE-AC06-76RL0 1830. 
For neutron dosimetry, the conversion set most commonly used was developed from computer calculations performed at Oak Ridge National Laboratory (ORNL) more than 20 years ago (Auxier, Snyder, and Jones 1968). In these calculations, monoenergetic beams were assumed to be normally incident on a cylindrical phantom, $30 \mathrm{~cm}$ in diameter and $60 \mathrm{~cm}$ high, composed of a tissue equivalent material with a uniform density. For each neutron energy, the location that received the highest dose equivalent rate was identified, and the dose equivalent per incident particle for this location was used as the basis for the fluence-to-dose equivalent conversion factor for that incident energy. This data set was recommended by the National Council on Radiation Protection and Measurements (NCRP) in Report 38 (NCRP 1971) and is cormonly used in the nuclear industry.

Basing the conversion factors on calculations performed in a homogeneous cylindrical phantom has some clear shortcomings. A homogeneous cylinder cannot be expected to have the same radiation transport properties as a human torso, so the maximum dose equivalent in a homogeneous cylinder is a poor approximation of the dose equivalents to sensitive organs inside a human torso. Despite these shortcomings, the NCRP-38 conversion factors have been widely used. Using the maximum value in a cylindrical phantom guarantees a high degree of conservatism when estimating the hazards to a human being, so radiation protection decisions would seem to be safely made using these values.

Unnecessary conservatism could become a problem, however, under changes that are being proposed in the methodologies for assessing dose equivalents due to external sources of neutrons. Increases in quality factors $(Q)$ might be implemented in the near future, and Publication 40 of the International Commission on Radiation Units and Measurements (ICRU 1986) contains a proposed definition of $Q$ as a function of lineal energy. ICRU-39 (ICRU 1985) is proposing use of the dose equivalent at a depth of $1 \mathrm{~cm}$ into a $30-\mathrm{cm}$-diameter sphere as a primary quantity in radiation protection.

One feature common to all methodologies for evaluating dose equivalent resulting from exposure to external sources of neutrons is the reliance on assessments of the radiation field inside a human torso or inside a phantom 
designed to simulate a human torso. With new methodologies for assessing dose equivalent, or with the adoption of higher values of $Q$, it becomes very important to have a high degree of confidence in the techniques for assessing the radiation field inside a phantom.

While nearly all methodologies for assessing the radiation field inside a phantom rely primarily on calculational techniques, it is also possible to measure the radiation field inside a phantom. Measurements are more difficult because the measuring instruments disturb the media into which they are inserted, and it is often difficult to precisely construct an ideal phantom or to find a neutron source having the ideal qualities that can be called up in a calculation. Measurements are valuable, however, because they do not depend on a totally conceptual representation of the physical phenomena being studied. While the interpretation of a measurement often depends to some extent on the application of empirically derived equations or data, the incident radiation field and nuclear interactions in the phantom do not have to be approximated by a representative model.

For evaluating the doses inside a phantom exposed to neutron radiation, the researcher can use measurement techniques and calculational techniques that complement each other. The tissue equivalent proportional counter (TEPC) is a detector that produces electronic pulses which are proportional in size to the linear energy transfer (LET) of the particle causing the pulse. A collected spectrum of pulses can therefore be analyzed to determine the dose received by the detector at a given location in a phantom due to the neutron and photon fluences there. A computer code based on the Monte Carlo neutron transport method, on the other hand, uses a statistical simulation of neutron interactions with particles in a phantom to determine the distribution of neutrons and photons at different locations inside the phantom. These distributions can then be analyzed to determine the doses at a number of locations. Since the two techniques employ different approaches to determining dose, a comparison of results generated by each can give a good indication of their reliability.

This report describes the study to determine dose profiles in a phantom. The mathematical and physical tools used in the study are described, the experimental procedures documented, and the results displayed and compared. 



\subsection{MEASUREMENT TECHNIQUE}

The measurements of depth dose profiles used small spherical tissue equivalent proportional counters (TEPCS) to measure neutron dose and miniature Geiger-Mueller (GM) tubes to measure photon dose. The detectors were inserted in a cylindrical phantom composed of A-150 tissue equivalent plastic. The phantom was exposed to neutrons emitted by an unmoderated 252cf source and to nearly monoenergetic neutrons emitted from a tritium target in a Van de Graaff accelerator.

\subsection{PHANTOM}

The design of the phantom was crucial because it had to represent a human torso and be easily modeled by the computer calculations. The design chosen for the phantom was a right circular cylinder. Although ICRU-39 (ICRU 1985) recommends a spherical design, the cylindrical phantom was chosen for this study because it is a better approximation of the human torso and has a geometrical shape that lends itself well to TEPC placement. The phantom, approximately $60 \mathrm{~cm}$ tall and $30 \mathrm{~cm}$ in diameter, is made of tissue equivalent (TE) Shonka A-150 plastic, a material nearly equivalent to human muscle tissue for neutron interactions.

Tissue equivalence was an important design criterion for the phantom since the dose profiles obtained are used to infer how energy from neutroninduced events is deposited in human tissue. The tissue equivalence of Shonka A-150 plastic is based on the equivalent composition of hydrogen and nitrogen relative to ICRU muscle tissue. Other human tissues, such as bone, or soft tissues, such as fat, have different compositions and densities, but muscle is commonly chosen as an appropriate "average" for tissue equivalency. Interactions with hydrogen and nitrogen are primarily responsible for the dose deposited in tissue from incident neutrons with energies up to about $10 \mathrm{MeV}$. All measurements were made in neutron fields with energies we1l within the limits for tissue equivalence of the Shonka A-150 material, so measurements in the phantom provided a good approximation to the absorbed dose in tissue. The composition of the Shonka A-150 plastic is summarized in Table 2.1; more detailed information is found in ICRU 26 (ICRU 1977). 
IABLE 2.1. Elemental Composition of Tissue Equivalent Plastic and Propane-Based Tissue Equivalent Gas

\begin{tabular}{|c|c|c|c|}
\hline Element & $\begin{array}{l}\text { ICRU Muscle } \\
\text { Tissue } \\
\end{array}$ & $\begin{array}{l}\text { Percent Weight } \\
\text { Shonka A-150 } \\
\text { Plastic } \\
\end{array}$ & $\begin{array}{c}\text { Propane-Based } \\
\text { TE Gas }\end{array}$ \\
\hline Hydrogen & 10.2 & 10.1 & 10.3 \\
\hline Nitrogen & 3.5 & 3.5 & 3.5 \\
\hline Oxygen & 72.9 & 5.2 & 29.3 \\
\hline Carbon & 12.3 & 77.6 & 56.9 \\
\hline Calcium & 0.007 & 1.8 & 0 \\
\hline Fluorine & - & 1.7 & 0 \\
\hline Total & $98.9(a)$ & 99.9 & 100 \\
\hline
\end{tabular}

(a) The $1.1 \%$ remainder consists of sodium, magnesium, phosphorus, sulfur, and potassium.

The phantom was assembled from six identically shaped cylindrical slabs stacked on top of each other, as shown in Figure 2.1. Each 5 lab is $29.9 \mathrm{~cm}$ in diameter and $9.7 \mathrm{~cm}$ high. A clear plastic (polymethyl methacrylate) plate, $2.7 \mathrm{~cm}$ high and $29.9 \mathrm{~cm}$ in diameter, was placed on top of the six slabs to bring the total height of the phantom to $60.9 \mathrm{~cm}$ and to position the center of the detectors in the midplane of the cylindrical phantom. The plate was considered far enough away from the measurement locations so that the lack of tissue equivalence was not significant.

The top three A-150 slabs and the clear plastic plate had 13 positioning holes drilled parallel to the vertical axis. Nine holes were situated in one row across the diameter, and the other four formed a line perpendicular to the first nine holes, as shown in figure 2.2. The holes used for measurements in this study were labeled 1 through 9 in Figure 2.2, with hole 1 positioned closest to the neutron source. Each hole was designed to accommodate either a small TEPC, a GM tube, or a Shonka A-150 plastic plug. As many as 


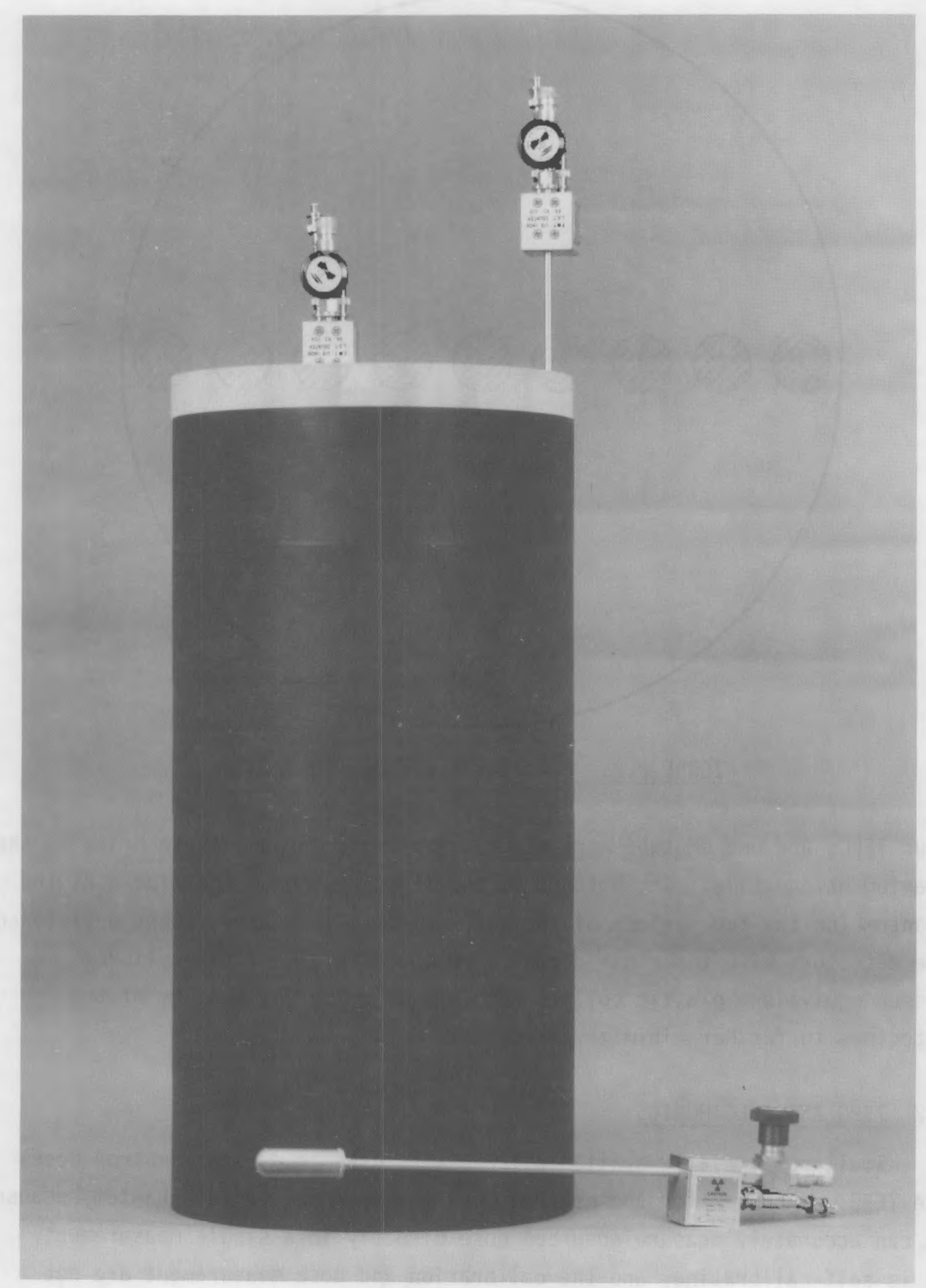

FIGURE 2.1. Phantom and TEPC Detector 


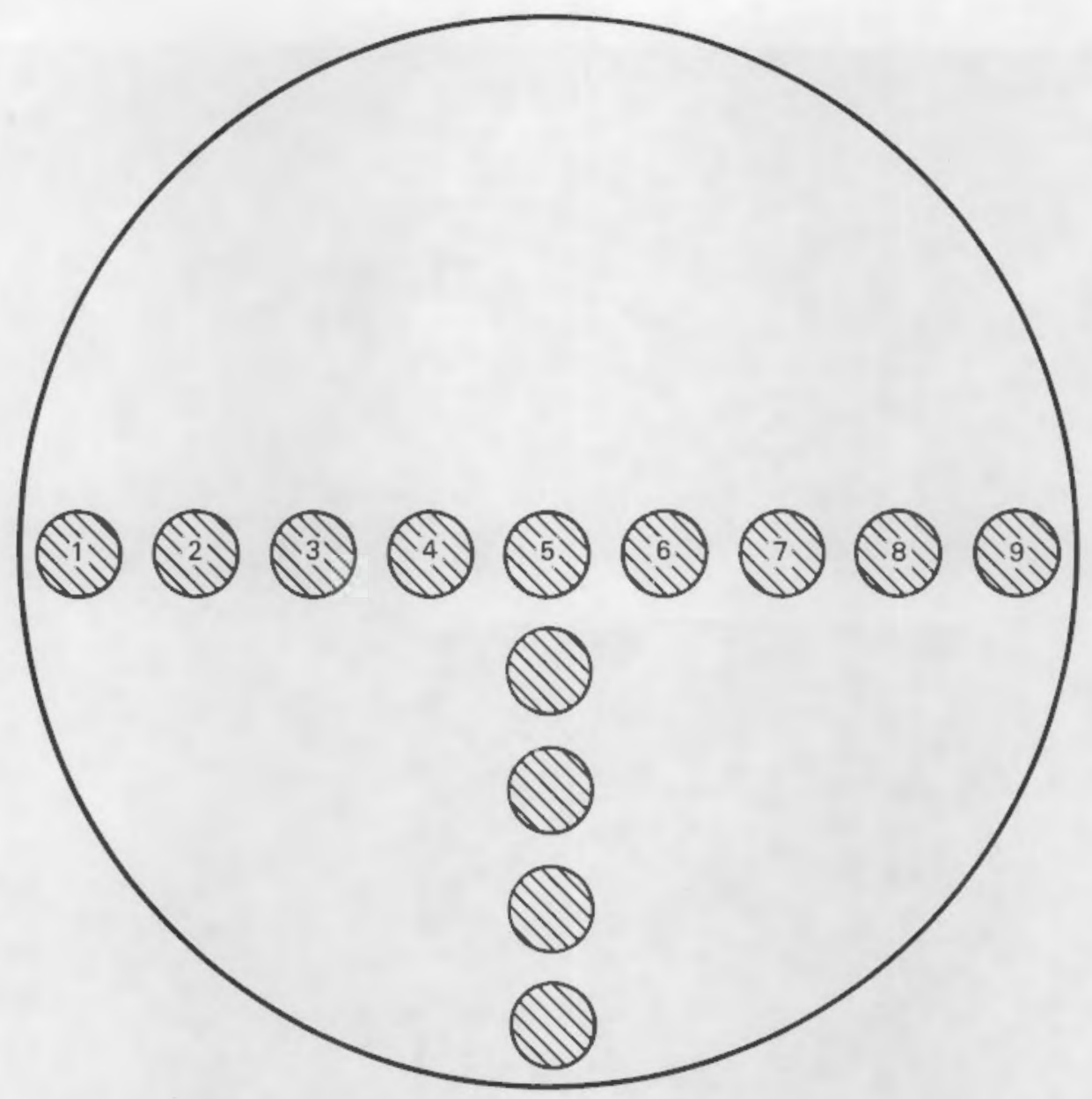

FIGURE 2.2. Detector Positions in Phantom

four TEPCs and one GM tube were placed vertically through these holes in the phantom at one time. The bottoms of the TEPCs rested at the middle of the phantom (on the top surface of the third slab). This arrangement positioned the detectors with their gas chambers on the midplane of the cylinder. Tissue equivalent plastic collars were wrapped around the necks of the detectors to further minimize air space.

\subsection{TEPC AND ELECTRONICS}

Small commercially available TEPCs were used to measure neutron dose. The TEPC was chosen for the neutron dose measurements in the phantom because it can accurately measure absorbed dose directly in a single measurement, it is self-calibrating, and the calibration and dose measurement are not 
dependent on neutron energy. The TEPC is the only instrument currently available which is used to measure absorbed dose from neutrons. and infer a quality factor.

\subsubsection{Description of TEPC Detector}

The TEPC detector is composed of a hollow 0.5-in.-inner-diameter sphere with $0.05-$ in.-thick walls constructed from Shonka A-150 plastic. A wire anode was stretched between the two poles of the sphere, and the sphere was filled with propane-based tissue equivalent gas (see Table 2.1 for gas composition). This spherical detector chamber was mounted inside a vacuum-tight aluminum shell on one end of a 10-in.-long aluminum stem, as shown in Figure 2.1. A junction box was located on the other end of the stem to permit connections for high voltage and signal transmission.

The detectors were filled with tissue equivalent propane-based gas at a low pressure of approximately 34 torr, which results in a mass of TE material that is equivalent to a sphere of tissue $1 \mu \mathrm{m}$ in diameter. The tissue equivalency of the detector chamber results in energy deposition that is equivalent to the energy deposition in human tissue.

The TEPC detector system consisted of the TEPC detector connected by a short cable to a preamplifier, a high-voltage power supply, $100 \mathrm{ft}$ of signal and high-voltage cables, a linear amplifier, an analog-to-digital converter $(A D C)$, a multichannel analyzer (MCA) capable of accepting simultaneous input from four ADCs, a tape cassette for data storage, and a personal computer used to process data. A NIM-bin power supply was used to hold the electronic modules (high-voltage power supplies, linear amplifiers, and ADCs) needed to run four detectors simultaneously. The TEPC was operated at a potential of approximately $+500 \mathrm{~V}$, with an amplifier gain set to position the calibrating proton drop point approximately in channel 300 . Figure 2.3 shows the MCA and full NIM-bin used for the measurements.

When the TEPC detector is exposed to incident neutrons, interactions between neutrons and atoms in the plastic detector wall produce recoil ions (primarily protons) that traverse the gas cavity. These ions deposit energy in the detector cavity that is equal to the LET of the particle multiplied by the path length in the sphere. The pulse size of the resulting signal is 


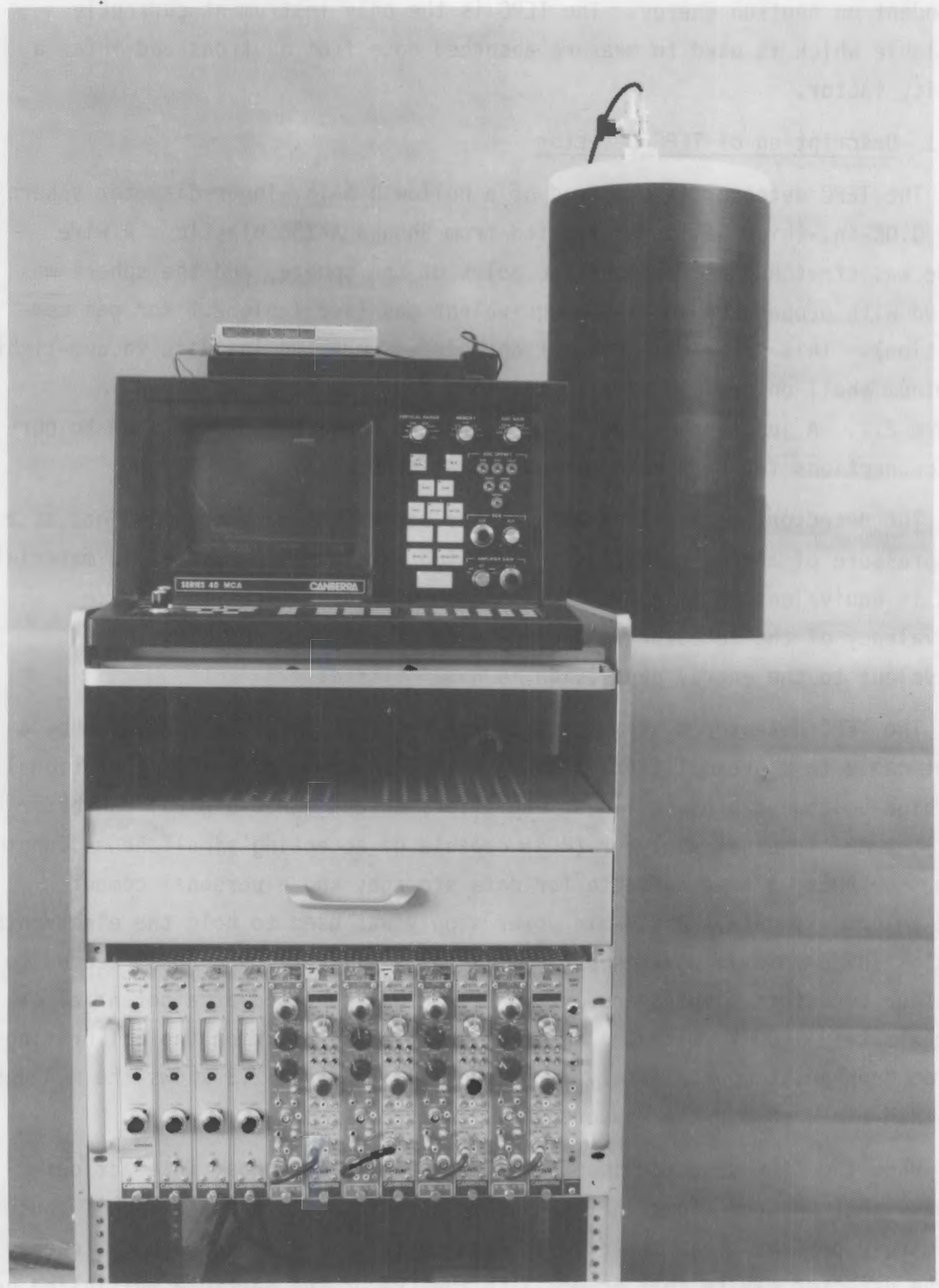

FIGURE 2.3. Phantom and Electronic Components 
proportional to the energy deposited by the traversing ion, so the distribution of pulses from the detector is characteristic of the LET distribution of the incident neutrons. The pulses from the detector are amplified and shaped by the preamplifier and amplifier and collected in a MCA.

\subsubsection{TEPC Data Analysis}

Each TEPC spectrum collected in this study was stored on a cassette tape and then transferred into a computer disk file. A computer program called TACI (Cummings 1984) was used to analyze each spectrum to determine the dose deposited in the detector and the average quality factor of the incident neutron field.

A TEPC neutron spectrum has a characteristic proton drop point that can be used for self-calibration. The proton drop point occurs at the point in the spectrum corresponding to the maximum proton stopping power, which usually occurs at approximately $100 \mathrm{keV} / \mu \mathrm{m}$, depending on the equivalent diameter of the detector sphere. For a spectrum with poor counting statistics, such as typically occurred in the low dose rate positions at the back of the phantom, the proton drop point is difficult to determine. However, a spectrum can also be calibrated using the detector's internal alpha source. Each detector contains a gravity-actuated ${ }^{244} \mathrm{Cm}$ alpha source. Alpha particles from this source produce a peak in the MCA spectrum. For calibration purposes, the location of the proton drop point was assumed to be approximately 1.05 to 1.1 times the location of the alpha peak. Thus, both reference points were used to establish the energy deposition scale.

A second characteristic of the spectrum of pulses from a TEPC measurement is the neutron start point. This point separates the low-LET events caused by electrons traversing the detector chamber from higher-LET events caused by protons and heavier ions. The electrons can come from three sources: photons ( $x$-rays and gammas) in the incident radiation field, photons produced in the detector wall by neutron interactions, or electronic noise from the cables and electronic components. The computer code used to analyze a TEPC measurement must discriminate the electronic noise from the photon-induced signals and then determine a gamma component and a neutron component of the total dose. It is unfortunate that both photon-induced sources of electrons are lumped together in a TEPC spectrum because the 
common discrimination between neutron dose and gamma dose would put the incident photons in the gamma-dose category and the neutron-induced photons in the neutron-dose category. The analys is done by the TACI computer code, however, uses all electron events to calculate the gamma dose and all higher-LET events to calculate the neutron dose.

\subsubsection{TEPC Uncertainties}

To test the accuracy and repeatability of the TEPC detectors, the four detectors used in this study were exposed to 144-keV neutrons coming from a filtered beam port in the Research Reactor at the National Bureau of Standards (now called the National Institute of Standards and Technology, or NIST). Nine different TEPC exposures were made in this beam, and the evaluated dose rates ranged from 1650 to $2450 \mathrm{mrad} / \mathrm{h}$, with a mean value of 1950. The accepted dose rate for this beam was $1900 \mathrm{mrad} / \mathrm{h}$, showing that the mean of the TEPC measurements agreed well with the accepted value. The standard deviation for the nine measurements was 236 , which is $12 \%$ of the mean.

Dose rates evaluated by TEPC measurements are presented in this report graphically with associated error bars. The error bars are derived from the following sources of uncertainty (McDonald et al. 1983):

- detector uncertainties (lack of exact knowledge of TEPC chamber volume: uncertainty in the pressure, density and composition of the TE gas; calibration)

- counting statistics

- experimental uncertainties.

The detector uncertainties can be set at about $5 \%$ from data in the report by McDonald et al. (1983). The counting statistics uncertainties experienced in this study ranged from $5 \%$ to $50 \%$, depending on the number of counts collected in the neutron region of the TEPC spectrum. In most TEPC measurements, more than 10,000 counts were recorded in the MCA channels corresponding to the neutron region of the spectrum, so these counting statistic uncertainties were under $10 \%$. However, in one or two of the measurements only a few hundred counts were recorded in these channels, so some uncertainties were as large as $50 \%$. Since the tests in the NIST 144-keV beam had a 
variability of $12 \%$ for nine identical runs with good counting statistics, a minimum uncertainty of $12 \%$ was assigned to TEPC runs.

The experimental uncertainties cover items such as knowledge of the incident neutron fields and positioning of the phantom. This component of the uncertainty varied with the specific setup for each measurement.

\subsection{GM COUNTER AND ELECTRONICS}

A complete accounting of the dose distribution in tissue must include the photon component of the dose as well as the neutron component. The photon dose can arise from photons emitted outside the phantom (i.e., gamnas that are part of the incident radiation field) or from photons produced in tissue by interactions of neutrons with atoms in the tissue (such as $n-\gamma$ reactions). In the studies described in this report, either the incident radiation fields contained a negligible amount of photons, or the incident photon field was well known so that the neutron-induced component could be determined.

Although the IEPC detector responds to photons, preliminary tests indicated that the detectors used in this study could not adequately assess the photon component of the dose. The low-LET events in a TEPC spectrum are easily lost in electronic noise generated by the electronic modules and cables. In the configuration used in this study, the long separation between the detector chamber and the preamplifier resulted in excessive noise in the low-pulse signals, making it impossible to make a good measurement of photon dose. Thus, it was necessary to use a different detector to measure the photon component of the dose.

Photon measurements were made with a commercially available miniature GM tube. The detector itself has a small cylindrical active volume, $0.48 \mathrm{~cm}$ in diameter and $0.64 \mathrm{~cm}$ long. The $\mathrm{fill}$ gas is neon with a halogen quenching agent. The detector chamber is on the end of a $26-\mathrm{cm}-1$ long aluminum stem, with an electrical connector box at the far end. The physical appearance of the GM detector is very similar to that of the TEPC, with the exception of the TEPC's aluminum shell over the detector sphere. 
The GM system consisted of the detector and a portable MCA. The MCA contained the high-voltage power supply, amplifier, and ADC electronic modules needed to run the detector. The high voltage was set to +475 volts. The signal from the detector was routed directly into the amplifier. A spectrum on the MCA from a GM measurement consisted of a single well-defined peak with virtually no background. Analys is of a measurement consisted of simply summing the counts under the peak and recording the MCA live time. The gamma-ray dose in tissue was computed from the measured counts using Equation (2.1):

$$
D_{\mathcal{\gamma}}=0.87 \mathrm{C} \cdot \mathrm{R}
$$

where $\quad D_{\gamma}=$ dose to tissue $(\mathrm{rad})$

$$
\begin{aligned}
0.87 & =\text { conversion from roentgen to tissue rad } \\
C & =\text { collected counts } \\
R & =\text { roentgen per count. }
\end{aligned}
$$

The detector manufacturer states that the response of the GM tube varies by no more than $10 \%$ for photons with energies ranging from $70 \mathrm{keV}$ to $2 \mathrm{MeV}$, and that the detector is almost completely insensitive to neutrons. Two different $G M$ tubes were used in this study, and the detector-specific calibration factors, $R$, were determined by exposing the detectors to a National Institute of Standards and Technology (NIST) traceable 137 Cs source. For GM 448 , the factor used to convert counts to roentgens was found to be $1.34 \times 10-8 \mathrm{R} /$ count. For $\mathrm{GM} \$ 525$, this calibration factor was found to be $6.24 \times 10^{-7} \mathrm{R} /$ count.

The uncertainties for a GM dose determination include the following (McDonald et al. 1983):

- detector uncertainties (calibration, neutron sensitivities), about 4\%

- counting statistics, about $1 \%$

- experimental uncertainties, variable. 
In each GM measurement, at least 10,000 counts were collected under the peak with almost no background to subtract, so that even in low-dose-rate regions of the phantom, the counting statistics uncertainty was less than $1 \%$. The experimental uncertainties vary with the measurement setup, but they are essentially the same as the experimental uncertainties associated with the TEPC measurements.

\subsection{QUANTITIES USED TO CHARACTERIZE IN-PHANTOM DEPTH PROFILES}

The radiation field inside the phantom was described using the quantity of absorbed dose rather than energy-dependent flux or dose equivalent. Flux could not be used as the basis for a comparison, since the GM and TEPC detectors could not directly determine flux. Dose equivalent would seem to be a good basis for comparison because it is the primary quantity used in radiation protection, but dose was chosen over dose equivalent for several reasons:

- Dose is a "physical" quantity, with a definition based on the energy deposited per unit mass. Dose equivalent is an "administrative" quantity, defined as the product of dose and quality factor. The definition of $Q$ is based on scientific evidence and may be related to physical quantities, but values for $Q$ are ultimately set by standards-setting comittees. It is quite likely that $Q$ values will change in the near future, but the definition of dose will not change.

- The algorithm used to analyze a TEPC run determines the average quality factor for the run based on the lineal energy distribution measured by the TEPC. The Monte Carlo neutron transport code does not determine lineal energy distributions, but would have to rely on neutron energy distributions to determine the average quality factor for a given evaluation. The two different methods for deriving $Q$ values would complicate the comparison.

- When the TEPC detectors were located inside the phanton, in many cases they were in regions with such low count rates that it would be very difficult to derive a representative quality factor value for the measurement. A TEPC measurement can be used to determine a reasonable value for the dose with a low number of counts, but much better statistics are needed to get a good value for $Q$. Using dose instead of dose equivalent allowed more data points to be compared. 


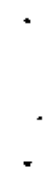




\subsection{CALCULATION TECHNIQUE}

The Monte Carlo method is a numerical procedure based on probability theory and is used in radiation transport problems involving systems of complex geometries. A set of histories is generated by following individual particles through successive collisions. The results of such collisions, e.g., a radiative capture or fission, or the energy and direction of an emerging neutron, are determined by sampling the various possibilities using random numbers. The statistical average of many histories describes the characteristics of a system.

\subsection{COMPUTER CODE ANALYSIS}

A radiation transport computer code based on the Monte Carlo method was used to model the nonsymmetrical geometries of detectors, phantoms, and neutron sources that were to be part of the measurements. The MCNP code was chosen as the most versatile Monte Carlo code that was readily available (RSIC 1983). A VAX version of MCNP was obtained from the Radiation Shielding Information Center (RSIC) at Oak Ridge National Laboratory.

\subsubsection{Monte Carlo Neutron and Photon Transport Code}

The computer code MCNP (RSIC 1983) was developed by the Radiation Transport Group in the Applied Theoretical Physics Division at Los Alamos National Laboratory. MCNP is a general purpose, continuous energy, generalized geometry, time-dependent, coupled neutron-photon Monte Carlo transport code. The code works in three modes: neutron transport only, combined neutron-photon transport, and photon transport only. The combined neutron-photon transport is actually neutron transport combined with neutron-induced photon production and transport.

The MCNP code was chosen for this study because of the following features: flexible three-dimensional modeling capabilities, a variety of standard sources, an elaborate selection of tallies, and extensive libraries of cross-section data. The MCNP code uses combinatorial geometry in which cells

VAX and VAX/VMS are registered trademarks of Digital Equipment Corp., Maynard, Massachusetts. 
are defined by the intersections, unions, and complements of the regions bounded by surfaces. The user can choose from all the surfaces of analytical geometry to define the modeled regions. Standard source geometries available in MCNP include an isotropic point source, an outward cosine distribution on a spherical surface, an inward cosine distribution on a spherical surface, a uniform distribution in a volume, and a plane-wave source. Source biasing can be used with any of these geometries. The tallies calculated by MCNP for output consist of the fluence at a point, across a surface, across a segment of a surface, or within a cell volume. The tally structure can be defined by the user as a function of energy, time, or direction.

\subsubsection{Cross-Section Libraries}

The cross-section set used with MCNP in this study included a photon cross-section library, a continuous energy neutron cross-section library, and a discrete energy neutron cross-section library. In the discrete energy library, the data have been collapsed into 240 energy groups. Included in the neutron cross-section libraries are photon production cross sections and neutron heating numbers. The cross-section data used by MCNP comes from three main sources: the Evaluated Nuclear Data File (ENDF/B-IV or ENDF/B-V), the Evaluated Nuclear Data Library (ENDL), and the Atomic Weapons Research Establishment (AWRE). It reproduces the original cross-section evaluation to within 0.1 to $0.5 \%$. All neutron reactions are accounted for in the energy range from about $0.00001 \mathrm{eV}$ to about $20 \mathrm{MeV}$, and photon interaction cross sections cover the energy range 0.001 to $100 \mathrm{MeV}$.

\subsubsection{VAX, HP-9000 Computer Environments}

For this study, MCNP was run on a VAX-11/750 superminicomputer and an HP-9000/550 supermicrocomputer. The VAX and HP-9000 computers are virtual memory, 32-bit single precision machines. The version of MCNP received from the RSIC had to be processed using a code called PRPR (RSIC 1983). By defining special variables for virtual memory, 32-bit single precision, and the VAX/VMS operating system, PRPR created a VAX-specific FORTRAN version of MCNP, which was then compiled and linked. The version of MCNP used on the

- HP-9000 and HP-9000/550 are registered trademarks of the HewlettPackard Corp., Palo Alto, California. 
HP-9000 was converted from the VAX version. Verification runs were made using both versions to check the code's performance against the specifications in the manual. The cross-section data also came with a processing code called MAKXSF, which trans lates the original data from EBCDIC or ASCII into binary format while creating a subset of the original library containing only user-specified isotopes and elements.

\subsection{CALCULATION MODEL}

Several sets of measurements were performed, all using a cylindrical phantom and $0.5-i n$. TEPCs with various neutron sources external to the phantom. In each case, the model for the phantom and the TEPCs was the same.

The phantom was modeled as a cylinder with the dimensions and chemical composition described in Section 2.1. The A-150 plastic was assumed to have a density of $1.12 \mathrm{~g} / \mathrm{cm}^{3}$. The phantom model was altered from run to run to reflect the presence of a detector in the positioning hole; the hole was filled with plastic material when the position was not occupied by a detector.

The TEPC used to measure the neutron dose in the phantom consisted of a small TE plastic sphere encased in a thin aluminum cylinder with a $0.75-i n$. outside diameter. The sphere was filled with a propane-based TE gas at 34 torr. During the initial stages of setting up the computer model, a single TEPC was modeled as a spherical wall of TE plastic filled with propane and also as one homogeneous sphere of tissue equivalent material with a density of $0.47 \mathrm{~g} / \mathrm{cm}^{3}$ to conserve the total number of molecules. Using a bare $252 \mathrm{Cf}$

- point source at a 1-m distance, both the detailed model and the homogeneous model produced similar results for a neutron flux tally averaged over the total volume of the detector $\left(713 \mathrm{n} / \mathrm{cm}^{2}-\mathrm{s}\right.$ for the detailed model versus $716 \mathrm{n} / \mathrm{cm}^{2}-\mathrm{s}$ for the homogeneous model) and a neutron point detector tally at the center of the detector $\left(696 \mathrm{n} / \mathrm{cm}^{2}-\mathrm{s}\right.$ versus $\left.694 \mathrm{n} / \mathrm{cm}^{2}-5\right)$. Since the more detailed model took about 25\% more computer time, the homogeneous model with a volume-averaged flux tally was used in all subsequent calculations involving the TEPCs and phantom. 
All the neutron transport calculations included neutron-induced photon production and transport. The photon component of the dose must be addressed when dealing with a high scattering medium such as tissue, where the neutrons undergo many collisions and produce a significant amount of photons that contribute to the whole body dose. In most cases explored by this study, the only significant source of photons was neutron interaction in the phantom, but in one instance a source photon transport calculation had to be performed because of the magnitude of source photons compared with the source neutrons.

The calculations performed by MCNP determined volume-averaged particle flux tallies over the volume of the 1/2-in. spherical detector. Since MCNP normalizes all results to the number of histories run, the result is actualiy fluence $\left(1 / \mathrm{cm}^{2}\right)$ per source particle. The normalized fluence was then multiplied by the source term (i.e., neutrons/second) to give results in terms of flux $\left(\mathrm{n} / \mathrm{cm}^{2} \mathrm{~s}\right)$. The flux in each energy group specified by the user was then multiplied by the appropriate kema factor to give the neutron (or gamma) dose rate.

Included with each flux value reported from an MCNP calculation is its relative statistical uncertainty, corresponding to one standard deviation. This means that the true value should lie within $* 1$ standard deviation of the reported result about $68 \%$ of the time. This uncertainty reflects only the random nature of the Monte Carlo technique and does not reflect uncertainties in the cross sections or in the modeling.

It would have been much easier to model the phantom as a homogeneous cylinder with no internal structure and calculate the flux at various depths, but even the small TEPCS perturb the neutron flux enough to cause significant differences. Therefore, to be able to compare measured values with calculated values, the detectors were also included in the model. To illustrate the importance of an accurate modeling of the structure of the detectors inside the phantom, test calculations were performed using both a detailed model for the detectors in the phantom and a homogeneous phantom. In both cases, the phantoms were exposed to neutrons from an unmoderated $252 \mathrm{Cf}$ source located on the plane that bisects the phantom, $1 \mathrm{~m}$ from the front of the phantom. Table 3.1 and Figures 3.1 and 3.2 show the difference between the estimates of flux and dose rate by the two models. 
TABLE 3.1. Calculated Fluxes in a Homogeneous Phantom and in a Phantom Containing Detectors

\begin{tabular}{|c|c|c|c|c|c|}
\hline \multirow{2}{*}{$\begin{array}{c}\text { Measure- } \\
\text { ment } \\
\text { Position }\end{array}$} & \multicolumn{5}{|c|}{ Neutron Flux in Phantom from 252 cf } \\
\hline & $\begin{array}{l}\text { Depth, } \\
\mathrm{cm}\end{array}$ & $\begin{array}{l}\text { Homogeneous } \\
\frac{n / \mathrm{cm}^{2}-\mathrm{s}}{}\end{array}$ & $\begin{array}{l}\text { Phantom } \\
\text { mrad/h }\end{array}$ & $\begin{array}{l}\text { Phantom } \\
\frac{n}{n / \mathrm{cm}^{2}-\mathrm{s}}\end{array}$ & $\frac{\mathrm{h} \mathrm{TEPCS}}{\mathrm{mrad} / \mathrm{h}}$ \\
\hline 1 & 1.7 & 3470 & 26.1 & 5060 & 33.2 \\
\hline 2 & 3.0 & 4270 & 24.2 & - & - \\
\hline 3 & 5.0 & 3570 & 19.2 & 3990 & 20.0 \\
\hline 4 & 8.3 & 2160 & 9.38 & 2590 & 10.2 \\
\hline 5 & 11.7 & 941 & 5.19 & 1170 & 4.93 \\
\hline 6 & 15.0 & 343 & 2.21 & 522 & 2.39 \\
\hline 7 & 18.3 & 261 & 1.62 & 318 & 1.14 \\
\hline 8 & 21.7 & 183 & 0.93 & 183 & 0.93 \\
\hline 9 & 25.0 & 23.6 & 0.22 & - & - \\
\hline 10 & 28.3 & 21.3 & 0.18 & 18.3 & 0.55 \\
\hline
\end{tabular}

The MCNP runs reported neutron and photon flux as a function of energy for each position in the model. To determine neutron and photon dose at these locations, the flux values were used as input to a post-processor computer code. This code applied fluence-to-dose conversion factors for each output energy group and summed over all energy groups to determine the dose for the tally point. Fluence-to-kerma factors for neutrons interacting in A-150 plastic were taken from the compilation of Caswell and Coyne (1980). Since all regions of interest were deep enough in the phantom to ensure electronic equilibrium, the approximation that kerma and dose are equivalent is valid, so kerma factors can be used to determine the absorbed dose. For photons, the calculated fluences were converted to dose using factors published in Stoddard (1965). 


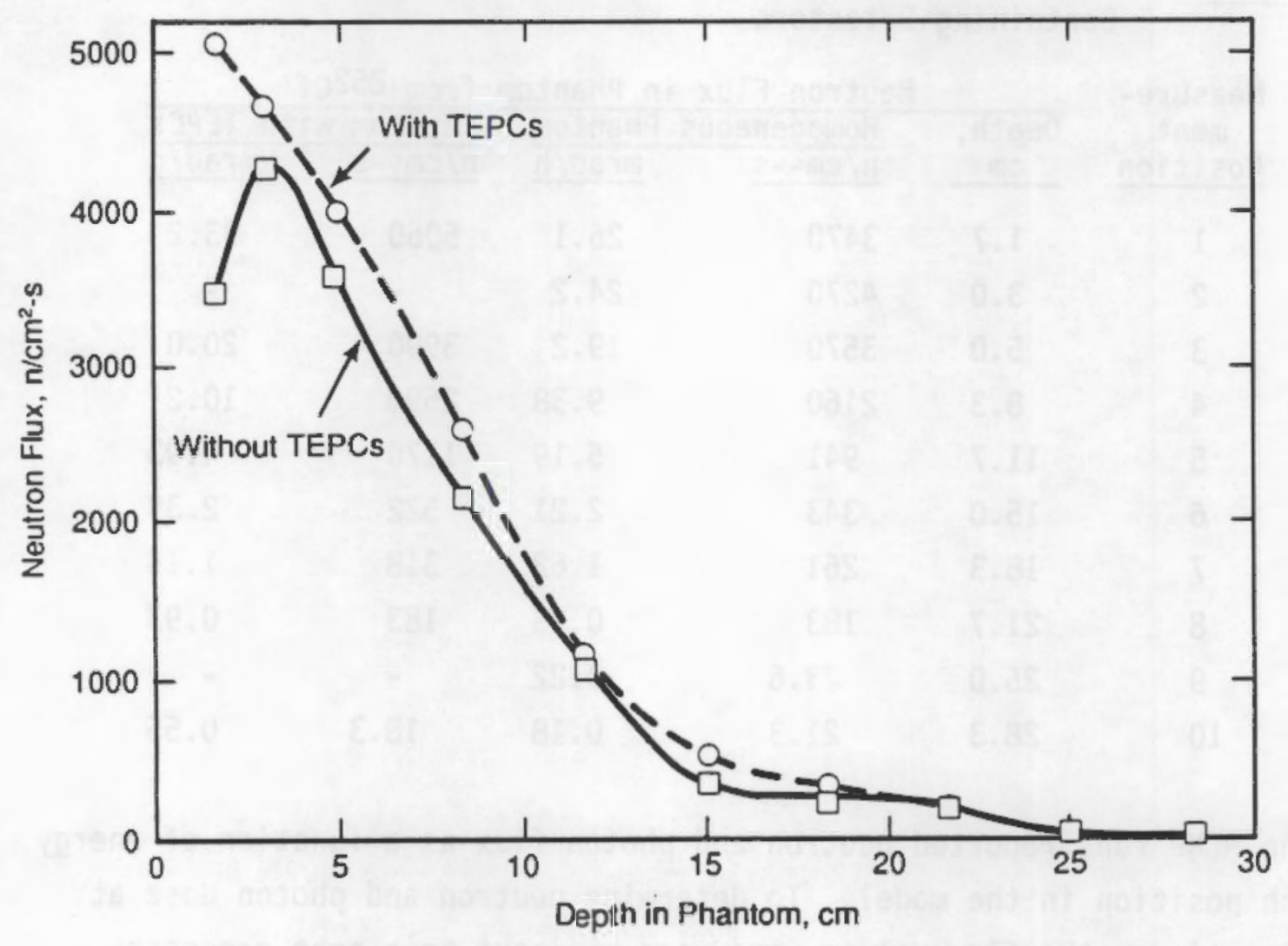

FIGURE 3.1. Neutron Flux Profile in Phantom 


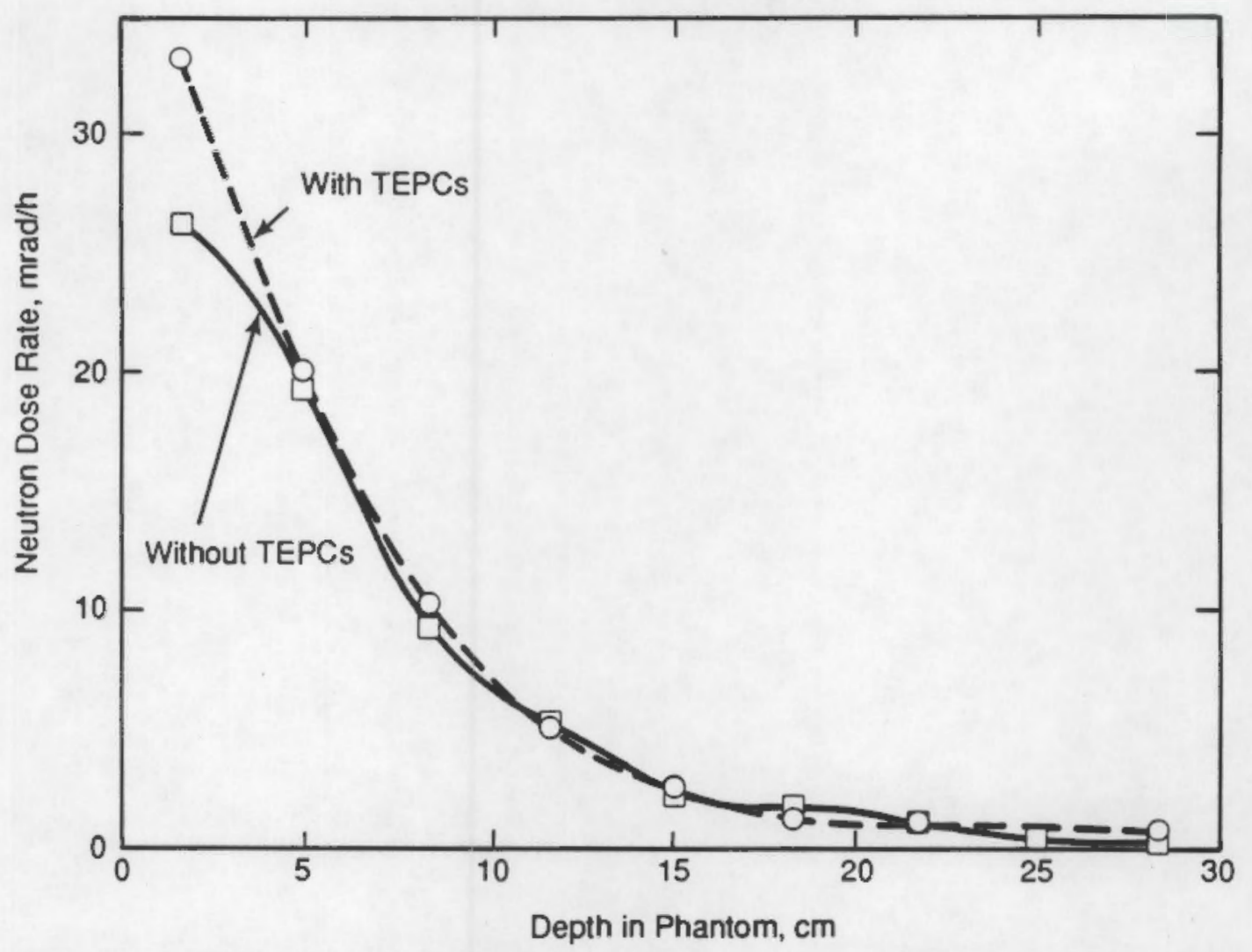

FIGURE 3.2. Neutron Dose Rate Profile in Phantom 



\subsection{DEPTH DOSE PROFILES RESULTING FROM 252Cf IRRADIATION}

This section describes measurements and calculations of dose profiles in the phantom exposed to neutrons from an unmoderated $252 \mathrm{Cf}$ source.

\subsection{SOURCE}

The first source used in this study was an unmoderated 252Cf source with a nominal size of $38 \mu \mathrm{g}$. The source emitted $9.6 \times 10^{7} \mathrm{n} / \mathrm{s}$ and $5.3 \times 10^{8} \mathrm{\gamma} / \mathrm{s}$ isotropically. Since $252 \mathrm{Cf}$ has a 2.645 -year half-life, the source strength decreased by $1.6 \%$ from the start of the phantom measurements to the final measurements, performed a month later. The source strengths used in calculations represented values for the middle of the measurement time period. With the decrease in source strength included as one of the uncertainties, the value for the radiation emission rate has an uncertainty of $2 \%$.

The $252 \mathrm{Cf}$ source exposed the phantom and detectors to a field of neutron radiation generated with a mean neutron energy of 2.1 to $2.3 \mathrm{MeV}$. Using the conversion factors listed in NBS-633 (Schwartz and Eisenhauer 1982), this $252 \mathrm{Cf}$ source would be expected to produce a dose equivalent rate of $370 \mathrm{mrem} / \mathrm{h}$ at $50 \mathrm{~cm}$. Assuming a quality factor of 10 for the neutron field surrounding a bare $252 \mathrm{Cf}$ source, the dose rate would be $37 \mathrm{mrad} / \mathrm{h}$ at a point in air $50 \mathrm{~cm}$ from the source.

Neutrons from the source irradiated the entire phantom, but the dose rate at the front of the phantom was nonuniform because of the size and curvature of the phantom, as shown in Figure 4.1. Since the top of the phantom was farther from the point neutron source than the middle of the phantom, the dose rate was $26.8 \mathrm{mrad} / \mathrm{h}$ ( $73 \%$ of the maximum dose rate) at the front of the top of the phantom.

\subsection{MEASUREMENTS}

Figure 4.1 shows the position of the unmoderated $252 \mathrm{Cf}$ source with respect to the phantom. The source was positioned $50 \mathrm{~cm}$ from the front face of the phantom and $30.5 \mathrm{~cm}$ from the bottom to align with the center of the gas chamber of the detectors located in the phantom. As shown in Figure 4.1, 


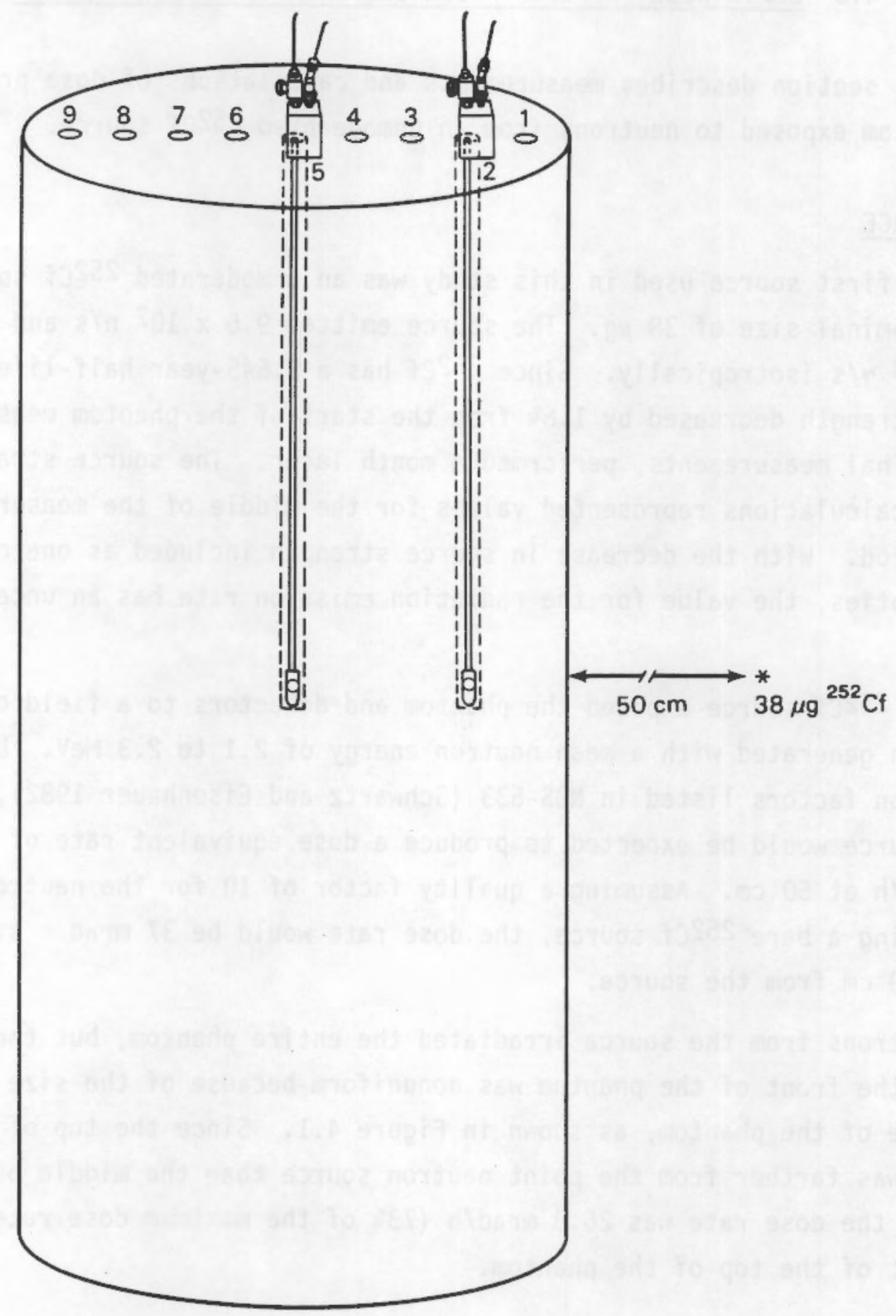

FIGURE 4.1. Exposure of Phantom to 252 Cf Source 
there were nine measurement locations for this study. All nine locations were located on the phantom midplane, all lying in a straight line. Tissue equivalent proportional counters were used in two locations at a time; Figure 4.1 shows the configuration with detectors in Measurement Positions 2 and 5. Neutron dose measurements were made with TEPCs in eight of the nine positions. Two TEPCs (1121 and 1122) were used in the phantom for each of five irradiation times (two sets of positions were measured twice); thus, for any irradiation, two measurement holes contained TEPCS with plastic collars and the other holes were filled with plastic plugs. Irradiation times varied from 2 to 19 hours depending on the count rate at the measurement positions. A TEPC measurement was also made in air at $50 \mathrm{~cm}$ from the source, with no phantom present. The measurement scheme and measured neutron dose rates are presented in Table 4.1.

In the first set of measurements, TEPC \#1121 was used in Position 1, while TEPC \#1122 was used in Position 3. Then, their positions were switched: TEPC $\# 1122$ in Position 1 and TEPC $\# 1121$ in Position 3 . The

TABLE 4.1. Measured Neutron Dose Rates in Phantom Exposed to Neutrons from an Unmoderated 252 Cf Source

\begin{tabular}{|c|c|c|c|c|c|}
\hline $\begin{array}{l}\text { Measurement } \\
\text { Position } \\
\end{array}$ & $\begin{array}{l}\text { Depth in } \\
\text { Phantom, } \\
\text { cm } \\
\end{array}$ & $\begin{array}{l}\text { Simultaneous } \\
\text { Measurement } \\
\text { Position } \\
\end{array}$ & $\begin{array}{c}\text { Integrated } \\
\text { Dose, } \\
\text { mrad } \\
\end{array}$ & $\begin{array}{c}\text { Count } \\
\text { Time, } \\
\mathrm{h} \\
\end{array}$ & $\begin{array}{c}\text { Measured } \\
\text { Dose Rate, } \\
\mathrm{mrad} / \mathrm{h} \\
\end{array}$ \\
\hline Air & - & - & 98.2 & 2.7 & 36.1 \\
\hline $\begin{array}{l}1 \\
1\end{array}$ & $\begin{array}{l}1.7 \\
1.7\end{array}$ & $\begin{array}{l}3 \\
3\end{array}$ & $\begin{array}{l}176 \\
177\end{array}$ & $\begin{array}{l}4.7 \\
4.9\end{array}$ & $\begin{array}{l}37.2 \\
36.3\end{array}$ \\
\hline 2 & 5.0 & 5 & 156 & 7.5 & 20.8 \\
\hline $\begin{array}{l}3 \\
3\end{array}$ & $\begin{array}{l}8.3 \\
8.3\end{array}$ & $\begin{array}{l}1 \\
1\end{array}$ & $\begin{array}{l}58.1 \\
63.8\end{array}$ & $\begin{array}{l}4.7 \\
4.9\end{array}$ & $\begin{array}{l}12.3 \\
13.1\end{array}$ \\
\hline 4 & 11.7 & 6 & 108 & 17.5 & 6.19 \\
\hline 5 & 15.0 & 2 & 38.5 & 13.0 & 2.96 \\
\hline 6 & 18.3 & 4 & 28.6 & 17.5 & 1.64 \\
\hline 7 & 21.7 & 9 & 34.9 & 18.8 & 1.86 \\
\hline 8 & 25.0 & - & - & - & - \\
\hline 9 & 28.3 & 7 & 6.64 & 18.8 & 0.353 \\
\hline
\end{tabular}


results listed in Figure 4.1 show that the reproducibility of these two runs is good, with duplicate measurements always agreeing to within $7 \%$.

Photon measurements were made with GM tube $\$ 448$ in each of the nine positions. One position was measured for each irradiation time, with all other holes plugged with plastic. The irradiation times varied from less than 0.5 hour to 3 hours, depending on the count rate at the detector. Count rates were converted to dose rates using the formula presented in Section 2.3. The measurement scheme and results are presented in Table 4.2.

Figure 4.2 summarizes the measured dose rates in the phantom exposed to radiation emitted from $252 \mathrm{Cf}$. Three curves are plotted on the graph: a neutron dose curve for results of the TEPC measurements; a photon dose curve for results of the GM measurements; and a total curve for the sum of neutron and gamma doses. The points on the vertical axis (depth $=0 \mathrm{~cm}$ ) are for measurements made in air, $50 \mathrm{~cm}$ from the source, with no phantom present.

TABLE 4.2. Photon Dose Measurements in Phantom Exposed to Neutrons from 252 Cf Source

\begin{tabular}{|c|c|c|c|c|}
\hline $\begin{array}{l}\text { Measurement } \\
\text { Position } \\
\end{array}$ & $\begin{array}{c}\text { Depth in } \\
\text { Phantom, } \\
\mathrm{cm} \\
\end{array}$ & $\begin{array}{c}\text { Integrated } \\
\text { Counts } \\
\end{array}$ & $\begin{array}{c}\text { Count } \\
\text { Time, } \\
\mathrm{h} \\
\end{array}$ & $\begin{array}{c}\text { Measured } \\
\text { Dose Rate, } \\
\mathrm{mrad} / \mathrm{h} \\
\end{array}$ \\
\hline Air & - & 13,111 & 0.62 & 24.7 \\
\hline 1 & 1.7 & 10,104 & 0.39 & 30.0 \\
\hline 2 & 5.0 & 10,182 & 0.43 & 27.4 \\
\hline 3 & 8.3 & 10,125 & 0.51 & 23.2 \\
\hline 4 & 11.7 & 10,394 & 0.69 & 17.4 \\
\hline 5 & 15.0 & 10,761 & 0.95 & 13.2 \\
\hline 6 & 18.3 & 10,087 & 1.16 & 10.1 \\
\hline 7 & 21.7 & 10,525 & 1.64 & 7.50 \\
\hline 8 & 25.0 & 10,865 & 2.27 & 5.57 \\
\hline $\begin{array}{l}9 \\
9\end{array}$ & $\begin{array}{l}28.3 \\
28.3\end{array}$ & $\begin{array}{r}8,681 \\
10,011\end{array}$ & $\begin{array}{l}2.44 \\
2.81\end{array}$ & $\begin{array}{l}4.15 \\
4.15\end{array}$ \\
\hline
\end{tabular}




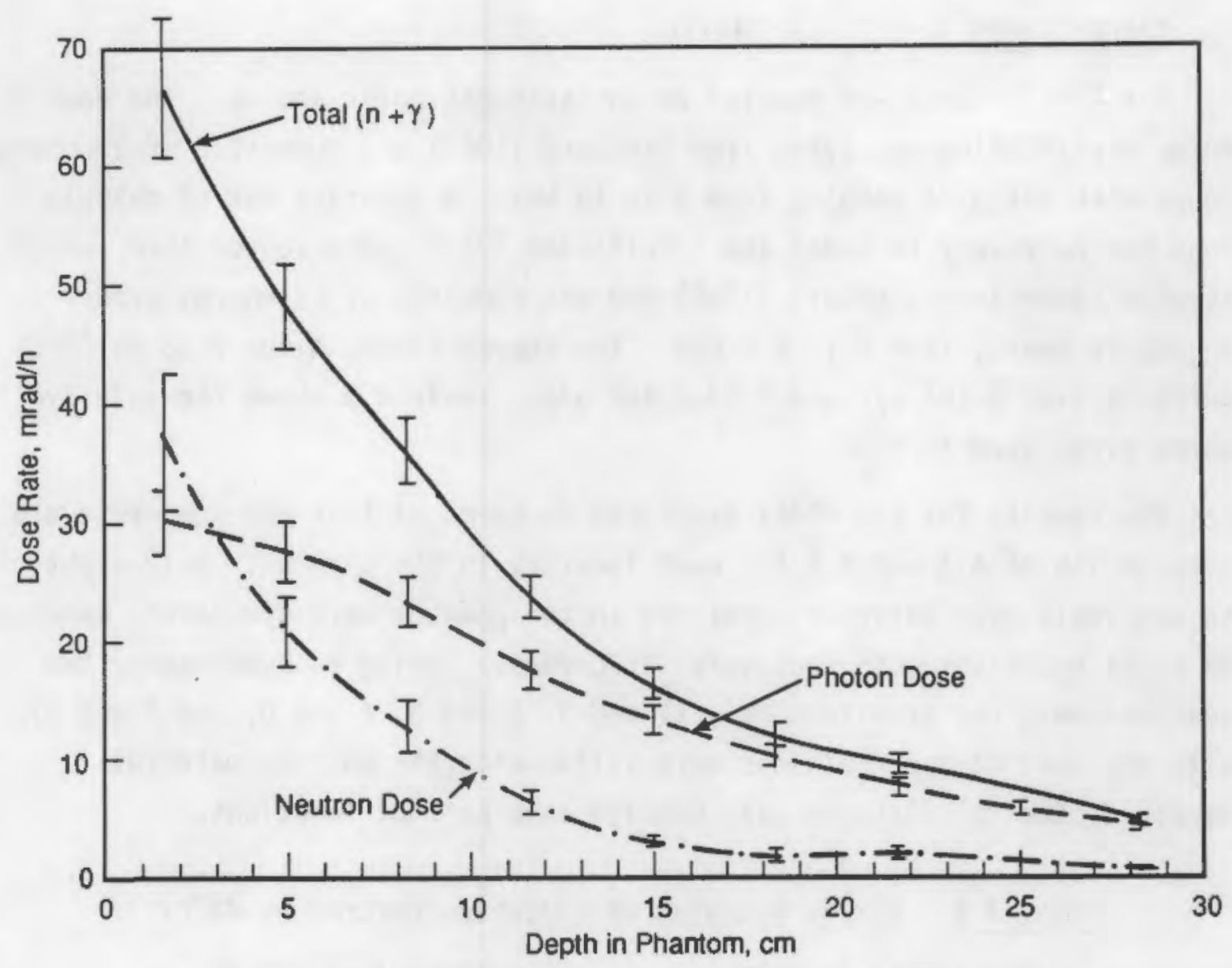

FIGURE 4.2. Measured Dose Rates from 252Cf

The error bars on the neutron curve are set around the measured values, as described in Section 2.0, to indicate the confidence in the TEPC measurements. The confidence interval is determined from the fixed uncertainties and each run's counting statistics uncertainty. The TEPC detector uncertainty (including counting statistics) for most detector locations was $12 \%$, with the deepest measurement location set at $30 \%$ because of the low number of counts collected. The uncertainty in the experimental conditions, including knowledge of the neutron source, phantom positioning, and other factors, was estimated to be $8 \%$. This experimental uncertainty was applied to both the TEPC and the GM measurements. The error bars for the GM runs were therefore set at $9 \%$ of the measured value to include the detector and experimental uncertainties. The error bars on the total curve are found by combining the uncertainties in the two component measurements. 


\subsection{CALCULATIONS}

The 252 Cf source was modeled as an isotropic point source. The neutron energy distribution was taken from Stoddard (1965) and consisted of 11 energy groups with energies ranging from 0 to $13 \mathrm{MeV}$. A separate set of calculations was necessary to model the significant 252 cf gamma source term, which was also taken from Stoddard (1965) and was composed of 13 energy groups ranging in energy from 0 to $6.5 \mathrm{MeV}$. The source strength for a $38-\mu \mathrm{g} 252 \mathrm{Cf}$ source is $9.64 \times 10^{7} \mathrm{n} / \mathrm{s}$ and $5.24 \times 10^{8} \mathrm{\gamma} / \mathrm{s}$. Table 4.3 shows the relative source terms used in MCNP.

The results for the 252Cf exposures in terms of flux and dose rate are given in Tables 4.4 and 4.5 for each location in the phantom. Only eight of the available nine detector locations in the phantom were simulated, matching the eight positions with successful TEPC runs. During each exposure, two locations were run simultaneously ( 1 and 3,2 and 5, 4 and 6, and 7 and 9) while the rest of the positions were filled with the phantom material. Therefore, the calculations also modeled each pair of locations.

TABLE 4.3. Energy Grouping of Radiation Emitted by 252Cf

\begin{tabular}{|c|c|c|c|c|}
\hline \multicolumn{3}{|c|}{ Neutrons from $252 \mathrm{Cf}$} & \multicolumn{2}{|c|}{ Photons from $252 \mathrm{Cf}$} \\
\hline & $\begin{array}{l}\text { nergy, } \\
\mathrm{MeV}\end{array}$ & $\begin{array}{l}\text { Relative Source } \\
\text { Strength, } \mathrm{n} / \mathrm{s}\end{array}$ & $\begin{array}{l}\text { Energy, } \\
\mathrm{MeV}\end{array}$ & $\begin{array}{l}\text { Relative Source } \\
\text { Strength, } \gamma / \mathrm{s} \\
\end{array}$ \\
\hline & -0.5 & 0.1152 & $0-0.5$ & 0.3480 \\
\hline 0.5 & -1.0 & 0.1523 & $0.5-1.0$ & 0.4312 \\
\hline 1.0 & -2.0 & 0.3128 & $1.0-1.5$ & 0.1286 \\
\hline 2.0 & -3.0 & 0.1893 & $1.5-2.0$ & 0.0582 \\
\hline 3.0 & -4.0 & 0.1152 & $2.0-2.5$ & 0.0166 \\
\hline 4.0 & -5.0 & 0.0658 & $2.5-3.0$ & 0.0083 \\
\hline 5.0 & -6.0 & 0.0230 & $3.0-3.5$ & 0.0042 \\
\hline 6.0 & -7.0 & 0.0165 & $3.5-4.0$ & 0.0023 \\
\hline 7.0 & -8.0 & 0.0053 & $4.0-4.5$ & 0.0013 \\
\hline 8.0 & -10.0 & 0.0041 & $4.5-5.0$ & 0.0006 \\
\hline 10.0 & -13.0 & 0.0009 & $5.0-5.5$ & 0.0004 \\
\hline & & & $5.5-6.0$ & 0.0002 \\
\hline & & & $6.0-6.5$ & 0.0001 \\
\hline
\end{tabular}


TABLE 4.4. Calculated Photon Dose Rates from 252Cf

\begin{tabular}{|c|c|c|c|c|c|}
\hline \multirow{2}{*}{$\begin{array}{l}\text { Measure- } \\
\text { ment } \\
\text { Position }\end{array}$} & \multirow[b]{2}{*}{$\begin{array}{c}\text { Depth, } \\
\mathrm{cm}\end{array}$} & \multicolumn{2}{|c|}{ Neutron-Induced Photons } & Source & \multirow{2}{*}{$\begin{array}{l}\text { Photons } \\
\text { Dose Rate, } \\
\text { mrad/h }\end{array}$} \\
\hline & & $\begin{array}{l}\text { Flux, } \\
y / \mathrm{cm}^{2} s \\
\end{array}$ & $\begin{array}{c}\text { Dose Rate, } \\
\mathrm{mrad} / \mathrm{h}\end{array}$ & $\begin{array}{l}F \operatorname{lux}_{3} \\
y / \mathrm{cm}^{2} \mathrm{~s}\end{array}$ & \\
\hline 1 & 1.7 & 1,200 & 3.02 & 21,500 & 21.5 \\
\hline 2 & 5.0 & 1,740 & 4.32 & 21,200 & 19.7 \\
\hline 3 & 8.3 & 1,480 & 3.66 & 20,800 & 17.7 \\
\hline 4 & 11.7 & 1,150 & 2.57 & 17,800 & 14.0 \\
\hline 5 & 15.0 & 987 & 1.82 & 12,800 & 10.8 \\
\hline 6 & 18.3 & 803 & 1.32 & 10,000 & 7.89 \\
\hline 7 & 21.7 & 471 & 0.87 & 7,590 & 5.86 \\
\hline 8 & 25.0 & - & - & - & - \\
\hline 9 & 28.3 & 369 & 0.59 & 3,940 & 3.31 \\
\hline
\end{tabular}

TABLE 4.5. Calculated Neutron and Photon Dose Rates from 252Cf

\begin{tabular}{|c|c|c|c|c|c|}
\hline \multirow{2}{*}{$\begin{array}{l}\text { Measure- } \\
\text { ment } \\
\text { Position }\end{array}$} & \multirow[b]{2}{*}{$\begin{array}{l}\text { Depth, } \\
\mathrm{cm}\end{array}$} & \multicolumn{2}{|c|}{ Total Neutron } & \multicolumn{2}{|c|}{ Total Photon } \\
\hline & & $\begin{array}{l}\text { Flux, } \\
\text { n/cm2s }\end{array}$ & $\begin{array}{c}\text { Dose Rate, } \\
\mathrm{mrad} / \mathrm{h}\end{array}$ & $\begin{array}{l}\text { Flux, } \\
\mathrm{g} / \mathrm{cm}^{2} \mathrm{~s}\end{array}$ & $\begin{array}{c}\text { Dose Rate, } \\
\mathrm{mrad} / \mathrm{h}\end{array}$ \\
\hline Air & 0. & 4,520 & 38.5 & - & - \\
\hline 1 & 1.7 & 5,710 & 37.5 & 22,700 & 24.6 \\
\hline 2 & 5.0 & 4,500 & 22.6 & 22,900 & 24.0 \\
\hline 3 & 8.3 & 2,920 & 11.6 & 22,300 & 21.3 \\
\hline 4 & 11.7 & 1,310 & 5.56 & 18,900 & 16.6 \\
\hline 5 & 15.0 & 589 & 2.69 & 13,800 & 12.6 \\
\hline 6 & 18.3 & 358 & 1.29 & 10,900 & 9.21 \\
\hline 7 & 21.7 & 214 & 1.05 & 8,060 & 6.73 \\
\hline 8 & 25.0 & - & - & - & - \\
\hline 9 & 28.3 & 117 & 0.62 & 4,310 & 3.90 \\
\hline
\end{tabular}

Photon dose rate values are shown in Table 4.4 for both the neutroninduced photons and the source photons. The major portion of the total photon dose rate is from the source photons, although the neutron-induced photons increase slightly with depth before starting to decrease.

The neutron and total photon dose rates are tabulated in Table 4.5. The neutron dose rate is significantly higher than the photon dose rate toward 
the front of the phantom, but the photon dose rate becomes higher after a depth of about $5 \mathrm{~cm}$. The neutron dose rate falls off rapidly with depth in the phantom because of the attenuation of the neutrons and the increasing distance from the source. The photon dose rate falls off much more gradually because of the production of more photons within the phantom and the lower photon attenuation of the phantom.

The calculated dose rates are presented in Figure 4.3. Three curves are again presented: a neutron curve, a photon (source plus secondary photons) curve, and a total (neutron plus photon) curve. The error bars represent the statistical uncertainty in the Monte Carlo technique, corresponding to one standard deviation.

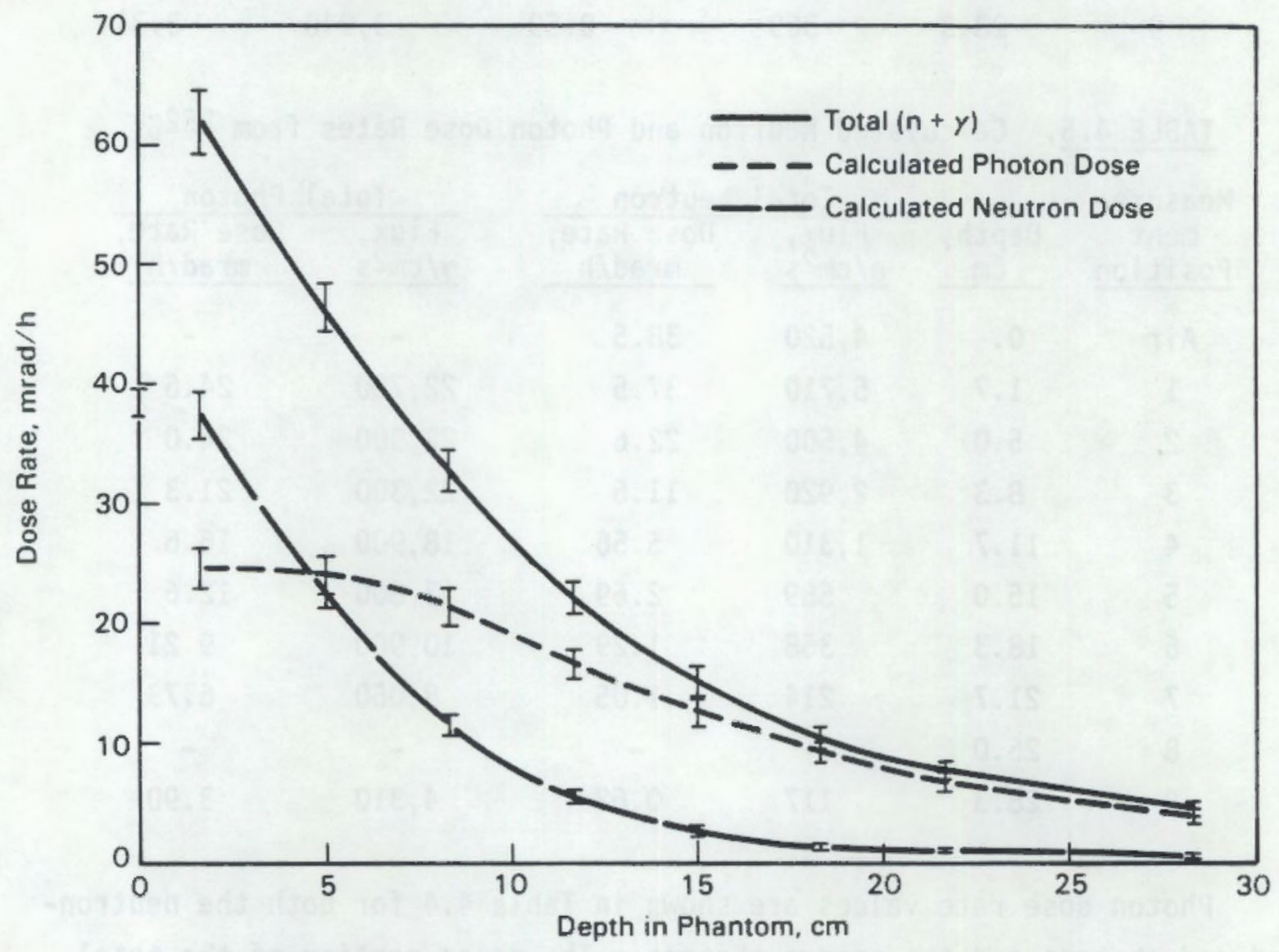

FIGURE 4.3. Calculated Dose Rates from 252cf 


\subsection{COMPARISON OF MEASUREMENTS AND CALCULATIONS}

The calculated neutron and photon dose rates for the 252 Cf source are compared with the measured values in Figure 4.4. Only the total photon dose rate is shown since the measurements with the GM counter do not distinguish between source photons and neutron-induced photons.

Nearly all points on the neutron dose curves show excellent agreement between the measured and calculated values: the error bars for measured and calculated neutron doses overlap for every position. The photon dose curves show a minor disagreement in the shallowest depth of the phantom and excellent agreement for depths greater than about $5 \mathrm{~cm}$.

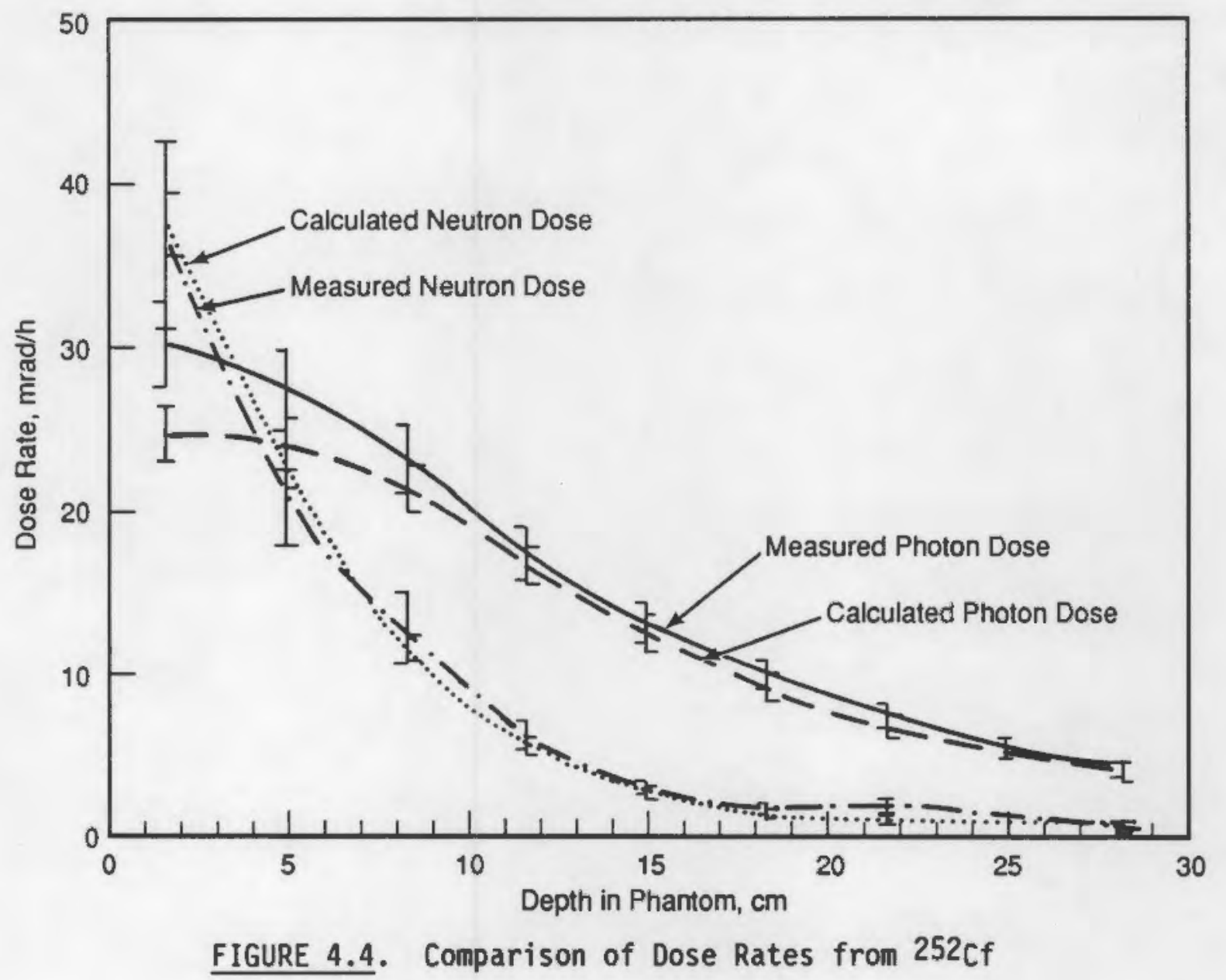





\subsection{DEPTH DOSE PROFILES RESULTING FROM 733-keV NEUTRONS}

For the second set of exposures, measurements were made at the PNL Van de Graaff accelerator. Neutrons produced by high-energy protons striking a tritium-doped target were used to irradiate the phantom.

\subsection{NEUTRON SOURCE}

The accelerator used for these irradiations was a Van de Graaff positive ion accelerator. In the accelerator, a beam of $1.8-\mathrm{MeV}$ protons was directed against a target, which was a copper-backed titanium hydride disk, $0.56 \mathrm{mg} / \mathrm{cm}^{2}$ thick, containing a high concentration of tritium. The interaction between the accelerated ion and tritium atoms produced neutrons with energies that depended on the angle of emission with respect to the incident proton beam. Neutrons coming off at an angle of $45^{\circ}$ had a maximum energy of $733 \mathrm{kev}$.

Since the energies of bombarding protons were degraded as the beam traversed the target, there was a variation in emitted neutron energy for a given emission angle that depended on target thickness. For a $45^{\circ}$ emission angle, this target emitted neutrons that varied in energy from 685 to $733 \mathrm{keV}$, a variation of $7 \%$. The choice of target thickness involves a tradeoff between high neutron emission rates (obtained from a thick target) and small variations in emission energies (obtained from a thin target). Tritium-doped targets typically vary in thickness from 0.235 to $1.2 \mathrm{mg} / \mathrm{cm}^{2}$. The target thickness of $0.56 \mathrm{mg} / \mathrm{cm}^{2}$ used in this study was chosen as a balance between high emission rate and low variation in emitted energy.

The emission rate of neutrons from the accelerator is not necessarily uniform over time. It varies with fluctuations in the proton beam current and with changing conditions of the target. A monitoring instrument was therefore used to monitor the neutron emission rate of the accelerator. The monitoring instrument used for this study was the Precision Long Counter (PLC), described in DePangher and Nichols (1966). Since the other two neutron sources used in this study had constant neutron emission rates over time, time was used as a normalization factor for comparing different measurements made on those sources, and dose rates were reported. For neutrons 
emitted by the accelerator, time could not be used as a normalization factor, but the PLC provided a means of normalization. Thus, measurements were compared by reporting dose per million long counts (MLC).

\subsection{MEASUREMENTS}

The phantom was positioned $50.5 \mathrm{~cm}$ from the target, $45^{\circ}$ to one side of the beam line for these measurements, as shown in Figure 5.1. The neutrons emitted from the target appeared to emanate from a point source. Thus, a line passing from the accelerator target through a diameter of the phantom midplane (and thus through the TEPC chambers) lay at a $45^{\circ}$ angle with the proton beam line, but lines to any other points on the phantom formed different angles with the proton beam line. Consequently, there was a distribution of incident neutron energies over the face of the phantom. This angular dependence on energy was coupled with the energy variation because of target thickness to produce the distribution of energies over the phantom face that is summarized in Table 5.1.

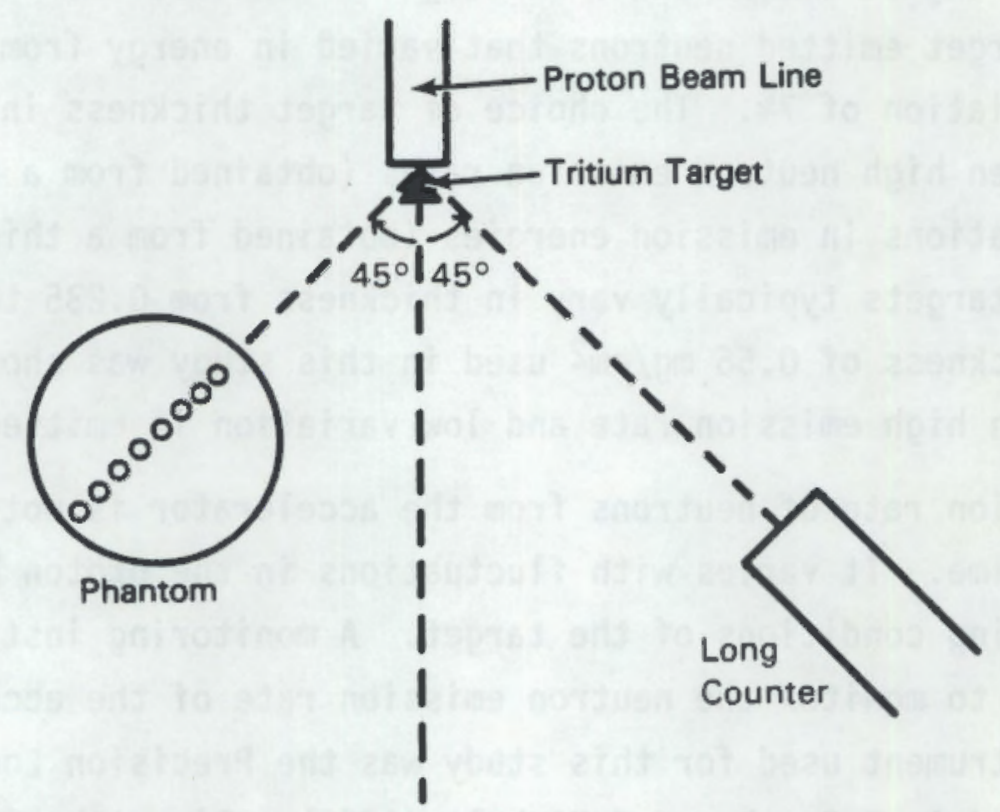

FIGURE 5.1. Experimental Configuration for Van de Graaff Accelerator with 733-keV Beam 
TABLE 5.1. Distribution of Neutron Energies over Phantom Face

\begin{tabular}{|c|c|c|}
\hline $\begin{array}{l}\text { Position on } \\
\text { Phantom }\end{array}$ & $\begin{array}{c}\text { Minimum } \\
\text { Neutron Energy, } \\
\text { keV }\end{array}$ & $\begin{array}{c}\text { Maximum } \\
\text { Neutron Energy, } \\
\mathrm{keV}\end{array}$ \\
\hline Top/Bottom & 611 & 655 \\
\hline \multicolumn{3}{|l|}{ Midplane } \\
\hline Inside Edge & 799 & 851 \\
\hline Center & 685 & 733 \\
\hline Outside Edge & 561 & 603 \\
\hline
\end{tabular}

A PLC was positioned $100 \mathrm{~cm}$ from the target and at an angle of $45^{\circ}$ from the beam line. The PLC consisted of a large-diameter $\mathrm{BF}_{3}$ tube inside a polyethylene moderator. Neutrons interacting with atoms in the polyethylene are thermalized and detected in the counter. The flux is then calculated using the distance between the front face of the detector, the energy of the neutron beam, and the response function. The PLC counted constantly to monitor the dose to the phantom, as the dose rate to the front of the phantom was not constant with time.

Measurements in the phantom exposed to this source were hampered by low dose rates and limited accelerator availability. Consequently, neutron measurements were made in only five of the nine phantom positions and photon dose measurements were made in three of the nine positions. In all counts, the data collection rates were low and statistical uncertainties in the counting were higher than in measurements made with the other two sources.

At all times in these measurements, three detector locations in the phantom were simultaneously occupied. In some cases, a detector was moved from one location to another while the two other locations were still being counted. As an example, three TEPCs were positioned in Measurement Positions 1, 7, and 9 and allowed to count for 5.6 hours (while the PLC collected 23.45 MLC). One TEPC was then moved from Measurement Position 1 to Measurement Position 3, while the remaining two TEPCs were left in Measurement Positions 7 and 9; all three were counted for an additional 3.75 hours (7.87 MLC). One TEPC detector was found to malfunction after the count data were analyzed using the TACI code (Cummings 1984), and the results from this 
detector had to be ignored. Detector Measurement Positions 6 and 9, therefore, appear as simultaneous measurement positions, but no results are presented for them in this study.

The results of the TEPC measurements of neutron dose are presented in Table 5.2, and the results of the GM measurements of photon dose are presented in Table 5.3. The results of both neutron and photon dose measurements are presented graphically in Figure 5.2.

The error bars associated with the data points in Figure 5.2 are larger than the error bars on the data points for the $252 \mathrm{Cf}$ measurements because of poorer counting statistics and larger uncertainties in the experimental conditions. The number of counts collected in the TEPC spectra were much lower

IABLE 5.2. Measured Neutron Doses in a Phantom Exposed to 733-keV Neutrons

\begin{tabular}{|c|c|c|c|c|c|}
\hline $\begin{array}{l}\text { Measurement } \\
\text { Position } \\
\end{array}$ & $\begin{array}{c}\text { Depth in } \\
\text { Phantom, } \\
\mathrm{cm} \\
\end{array}$ & $\begin{array}{l}\text { Simultaneous } \\
\text { Measurement } \\
\text { Position } \\
\end{array}$ & $\begin{array}{c}\text { Integrated } \\
\text { Dose, } \\
\text { mrad } \\
\end{array}$ & $\begin{array}{l}\text { Million } \\
\text { PLC } \\
\text { Counts } \\
\end{array}$ & $\begin{array}{c}\text { Measured } \\
\text { Dose, } \\
\mathrm{mrad} / \mathrm{MLC} \\
\end{array}$ \\
\hline Air & - & - & 26.3 & 10.53 & 2.50 \\
\hline 1 & 1.7 & 7,9 & 43.3 & 17.66 & 2.45 \\
\hline 2 & 5.0 & 4,6 & 53.2 & 54.83 & 0.970 \\
\hline 3 & 8.3 & 7,9 & 2.90 & 7.87 & 0.369 \\
\hline 4 & 11.7 & 2,6 & 7.60 & 54.83 & 0.139 \\
\hline 7 & 21.7 & $1,3,9$ & 0.778 & 25.77 & 0.0302 \\
\hline
\end{tabular}

TABLE 5.3. Measured Photon Doses in a Phantom Exposed to 733-keV Neutrons

\begin{tabular}{|c|c|c|c|c|c|}
\hline $\begin{array}{l}\text { Measurement } \\
\text { Position }\end{array}$ & $\begin{array}{c}\text { Depth in } \\
\text { Phantom, } \\
\mathrm{cm} \\
\end{array}$ & $\begin{array}{l}\text { Simultaneous } \\
\text { Measurement } \\
\text { Position } \\
\end{array}$ & $\begin{array}{c}\text { Integrated } \\
\text { Dose, } \\
\text { mrad } \\
\end{array}$ & $\begin{array}{l}\text { Million } \\
\text { PLC } \\
\text { Counts } \\
\end{array}$ & $\begin{array}{c}\text { Measured } \\
\text { Dose, } \\
\mathrm{mrad} / \mathrm{MLC} \\
\end{array}$ \\
\hline 1 & 1.7 & 4,6 & 0.555 & 1.15 & 0.48 \\
\hline 2 & 5.0 & 4,6 & 0.649 & 1.01 & 0.64 \\
\hline 3 & 8.3 & - & - & - & - \\
\hline 4 & 11.7 & 6 & 1.86 & 4.90 & 0.38 \\
\hline
\end{tabular}




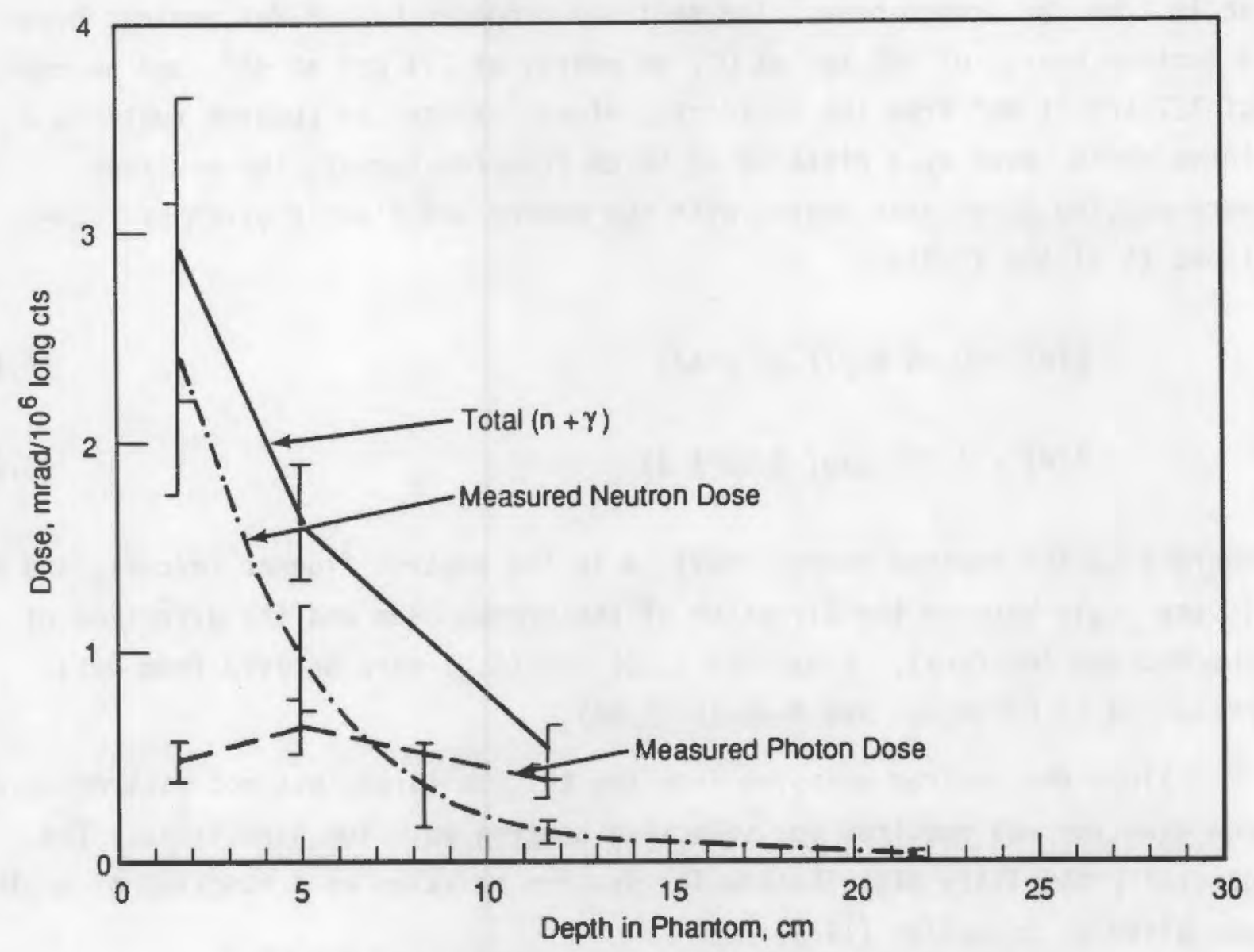

FIGURE 5.2. Measured Doses from 733-keV Neutrons

for this neutron source, causing the detector uncertainty (including counting statistics) to range from 16 to $50 \%$. The experimental uncertainties were estimated at $20 \%$ because of the increased difficulty in positioning the phantom (angle from the source was critical here but not important with the 252 (f source) and poorer knowledge of the actual neutron source. The conversion from PLC counts to fluence had some uncertainty associated with it, and the characterization of the energy characteristics of the neutron beam leaving the target is not as precise as the characterization of the neutron field near a bare $252 \mathrm{Cf}$ source.

\subsection{CALCULATIONS}

The neutrons are produced in a very small target that can be reasonably modeled as a point source. However, the neutron energy and yield vary with 
angle from the proton beam. The neutrons produced by $1.8-\mathrm{MeV}$ protons have a maximum energy of $996 \mathrm{keV}$ at $0^{\circ}$, an energy of $733 \mathrm{keV}$ at $45^{\circ}$, and an energy of $327 \mathrm{keV}$ at $90^{\circ}$ from the incident protons. Since the phantom subtends a large angle, even at a distance of $50 \mathrm{~cm}$ from the target, the neutrons were modeled as a point source with the energy and fluence given by Equations (5.1) and (5.2):

$$
\begin{aligned}
& E(\theta)=0.34 \exp (1.09 \cos \theta) \\
& \Phi(\theta)=41860 \exp (-0.0071 \theta)
\end{aligned}
$$

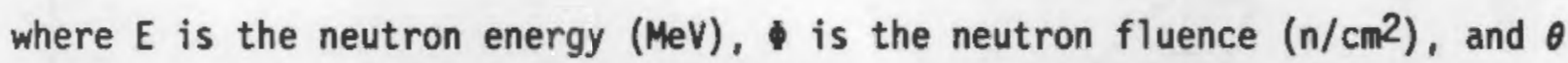
is the angle between the direction of the proton beam and the direction of the neutron (degrees). Equations (5.1) and (5.2) were derived from data presented in DePangher and Nichols (1966).

Since the neutron emission from the tritium target was not isotropic, a new equation was required for selecting neutron emission directions. The general probability distribution for neutron emission as a function of angle was given by Schaeffer (1973):

$$
P(\theta)=n=\frac{\int_{0}^{\theta}\left(\theta^{\prime}\right) d \theta^{\prime}}{\int_{0}^{180}\left(\theta^{\prime}\right) d \theta^{\prime}}
$$

where $P(\theta)$ is the probability distribution and $n$ is a random number between 0 and 1. When the expression for fluence given in Equation (5.2) is substituted into Equation (5.3), the result is

$$
\theta=-140.8 \ln (1-0.7214 n)
$$

Once the equation direction was chosen, the neutron energy could be found using Equation (5.1). 
The results of the anisotropic model were compared to results from a simple isotropic model using a single energy of $733 \mathrm{keV}$. The dose rate at a depth of $1.7 \mathrm{~cm}$ in the phantom was determined to be $2.31 \times$ $10^{-7}(\mathrm{mrad} / \mathrm{h}) /(\mathrm{n} / \mathrm{s})$ by the anisotropic model and $2.29 \times 10^{-7}(\mathrm{mrad} / \mathrm{h}) /(\mathrm{n} / \mathrm{s})$ by the isotropic model. The key factor does not seem to be in the modeling of the angular distribution of the source term but in the actual value of the source term in neutrons/second.

The source term was derived by converting long counts to fluence based on the efficiency of the PLC and then calculating the integral of the fluence over all angles. The value used was 46,700 source neutrons/long count for the calculations to convert the results from nomalized fluence to flux and dose rate in terms of long counts. The flux and dose rate profiles in the phantom are presented in Table 5.4 and Figure 5.3. The units for dose and flux are per MLC.

\subsection{COMPARISON OF MEASUREMENTS AND CALCULATIONS}

The calculated neutron and photon dose rates for exposure of the phantom to neutrons generated by the accelerator are compared with the measured results in Figure 5.4. The error bar for each position on the calculation curves corresponds to the uncertainty due to the Monte Carlo statistics of the given calculation, and the error bar for each point on the measurement

TABLE 5.4. Calculated Flux and Dose Distributions in a Phantom Exposed to 733-keV Neutrons

\begin{tabular}{|c|c|c|c|c|c|}
\hline \multirow{2}{*}{$\begin{array}{c}\text { Measure- } \\
\text { ment } \\
\text { Position }\end{array}$} & \multirow[b]{2}{*}{$\begin{array}{c}\text { Depth, } \\
\mathrm{cm}\end{array}$} & \multicolumn{2}{|c|}{ Total Neutron } & \multicolumn{2}{|c|}{ Total Photon } \\
\hline & & $\begin{array}{c}\text { Flux } \\
\mathrm{n} / \mathrm{cm}^{2}-\mathrm{MLC}\end{array}$ & $\begin{array}{l}\text { Dose Rate, } \\
\mathrm{mrad} / \mathrm{MLC}\end{array}$ & $\begin{array}{c}F \operatorname{lux} \\
I / \mathrm{cm}^{2}-M L C C\end{array}$ & $\begin{array}{l}\text { Dose Rate, } \\
\mathrm{mrad} / \mathrm{MLC}\end{array}$ \\
\hline 1 & 1.7 & $2.88 E+6$ & 2.98 & $6.61 E+5$ & 0.48 \\
\hline 2 & 5.0 & $2.03 E+6$ & 1.39 & $7.03 E+5$ & 0.50 \\
\hline 3 & 8.3 & $1.13 E+6$ & 0.67 & $9.46 \mathrm{E}+5$ & 0.68 \\
\hline 4 & 11.7 & $3.82 E+5$ & 0.18 & $3.74 \mathrm{E}+5$ & 0.24 \\
\hline 5 & 15.0 & - & - & - & - \\
\hline 6 & 18.3 & - & - & - & - \\
\hline 7 & 21.7 & $7.67 E+4$ & 0.03 & $4.21 E+5$ & 0.13 \\
\hline
\end{tabular}




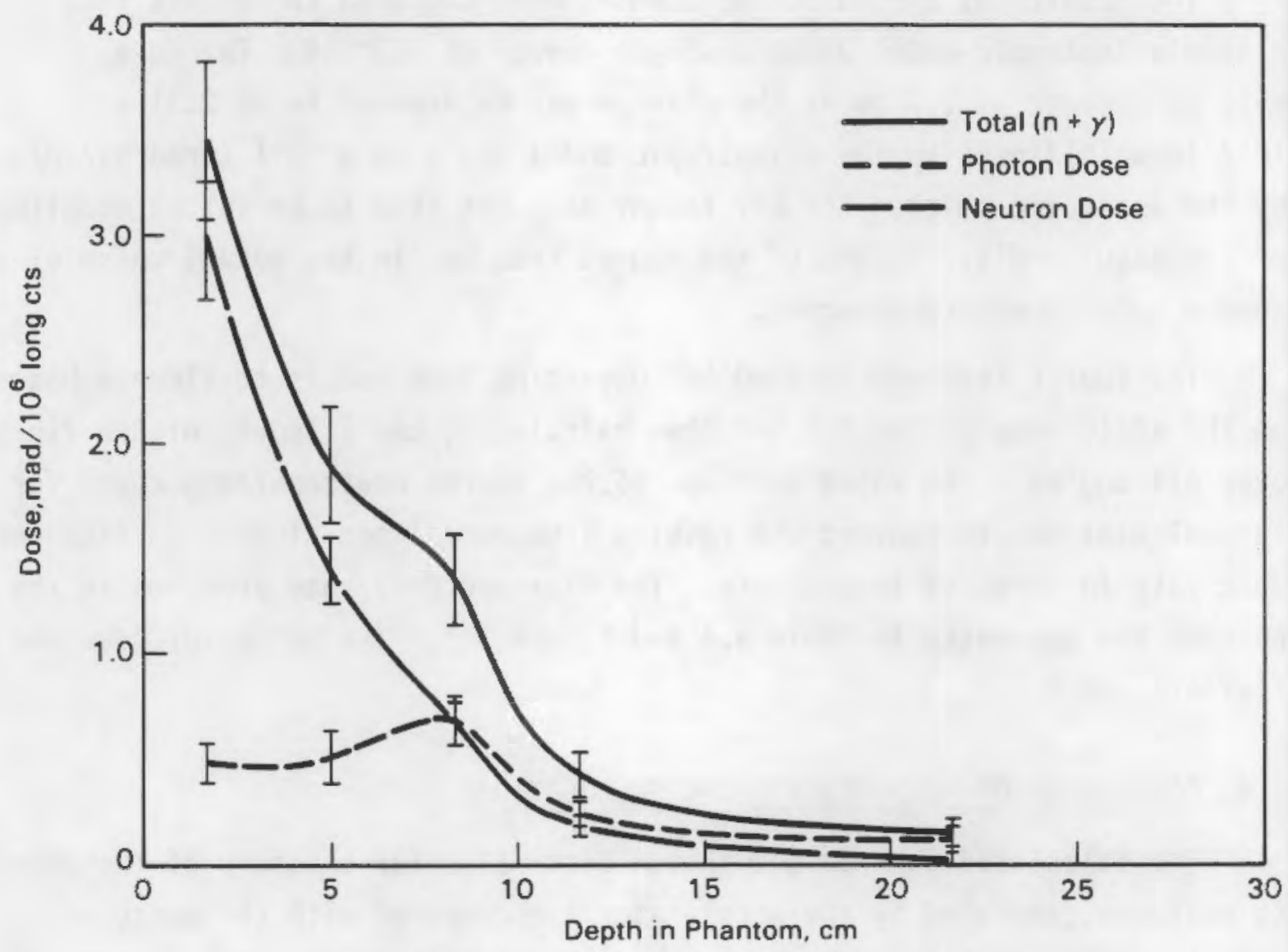

FIGURE 5.3. Calculated Doses from 733-keV Neutrons

curves corresponds to detector and experimental uncertainties in each measurement. Since the error bars for corresponding measurements and calculations overlapped in nearly every case, this comparison demonstrates a fundamental agreement between measurements and calculations.

The shapes of the neutron curves are very similar, with steep slopes at shallow depths in the phantom, then flattening out when measured deeper in the phantom. The curve for calculated doses lies higher than the measurements curve, probably because of uncertainties in estimating the actual fluence at the front of the phantom per long count. The disagreement between the calculated and measured doses was less than $30 \%$ for most locations. 


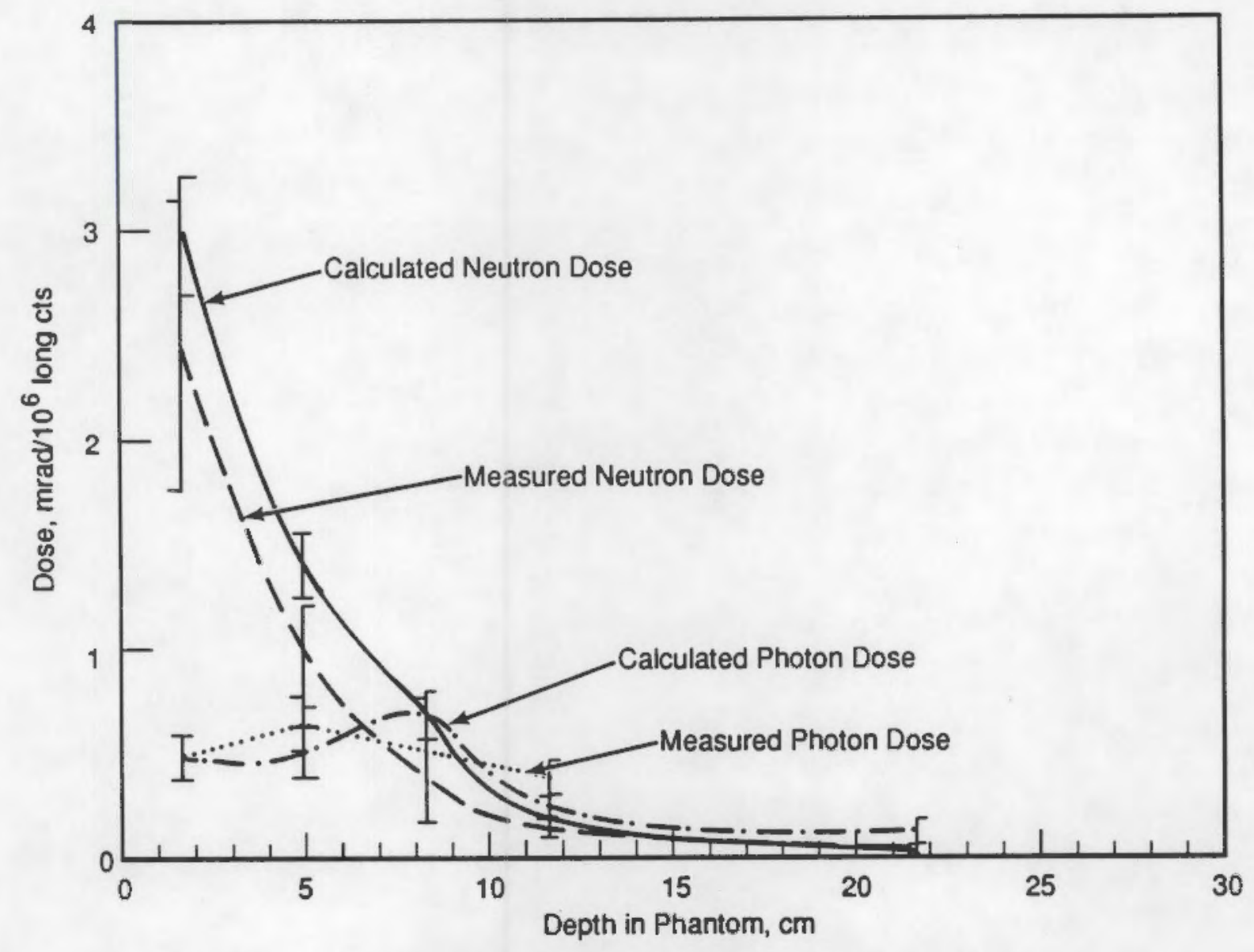

FIGURE 5.4. Comparison of Doses from 733-keV Neutrons

The two photon curves in Figure 5.4 were very similar, indicating good agreement between the calculations and measurements. Unfortunately, no measurement was made in the fourth detector position $(8.3 \mathrm{~cm}$ deep); it would be interesting to see if that measurement showed an increase in dose over the value in Position $3(5.0 \mathrm{~cm}$ deep) as seen in the calculations. 



\subsection{CONCLUSIONS}

This study compares depth dose measurements to calculations and demonstrates some of the reasons for using each of the two different approaches to determining neutron doses. The study shows that each approach has strengths and weaknesses.

\subsection{RESULTS OF COMPARISONS}

Comparisons were made between measurements and calculations for phantoms exposed to two different types of neutron sources. For both neutron sources, the error bars for corresponding data points overlapped in nearly every case. This overlap demonstrates a basic agreement between the measurements and the calculations. For the 733-keV neutron beam generated by the Van de Graaff accelerator, the measurement and the calculation curves were moderately close to each other; the comparison was limited primarily by poor counting statistics and experimental uncertainties such as the characterization of the neutron field. The comparison between the measured and calculated dose profiles was excellent in the phantom exposed to neutrons from $252 \mathrm{Cf}$. Because exposures at the $252 \mathrm{Cf}$ source included higher count rates and, therefore, better counting statistics than the $733-\mathrm{keV}$ source, it was easier to get reproducible results.

The main difficulties encountered in this study could be traced to the nature of the neutron sources. Ideally, the study would have used a number of monoenergetic neutron sources, with beam, isotropic, and point source geometries. It would have also used a few realistic radiation fields, duplicating the fields to which workers are actually exposed. In reality, it is difficult to find truly monoenergetic sources of neutrons, and for any given neutron energy there is usually only one source geometry that can reasonably be used.

The Van de Graaff accelerator gives a fjeld that is nearly monoenergetic at a given angle off the target, but a phantom subtends a large enough angle to result in a large distribution of neutron energies. Moving the phantom farther back would have resulted in a smaller spread of energies, but lower dose rates. Furthermore, the accelerator is limited to a point source 
geometry. The biggest limitation in the use of the accelerator as a neutron source was the low intensity of the neutron field, resulting in the low count rates in the phantom. Longer counts or higher count rates would have been beneficial in improving the quality of the measurements.

The measurements performed at the $252 \mathrm{Cf}$ source are perhaps more significant because they are closer to a realistic radiation field in which workers would actually be exposed. Most neutron fields consist of a combination of energies rather than a monoenergetic source. Thus, the comparison of measurements and calculations in a field consisting of a range of energies is a better test of the performance of the techniques in a realistic health physics application. It would enhance this study to include more realistic neutron fields, such as a moderated 252Cf source, neutrons from another isotope such as plutonium, or a reactor spectrum. The difficulty in choosing realistic spectra is the problem of finding one that is well characterized in terms of directionality and energy distribution.

\subsection{SIGNIFICANCE TO HEALTH PHYSICS APPLICATIONS}

The results of this study are significant because they demonstrate a basic agreement between two different techniques for assessing doses resulting from incident neutrons. The calculations depend on nuclear interaction cross sections and particle transport algorithms, while the measurements depend on electronic signals that are triggered by dose-depositing interactions, then processed by electronic modules and analyzed using empirically derived algorithms. When both techniques give basically the same results, health physicists can have a good degree of confidence in the results generated by either technique. Each technique has unique strengths and weaknesses, however, that make it applicable in some situations but not others.

To accurately calculate neutron dose, the radiation source must be well known. Every shield, scatterer, or other physical feature also must be well known and easily described as a numerical value that can be input into a computer code. Thus, certain realistic neutron fields, such as the neutron field inside a reactor containment, could not be used in this study. Such fields are best characterized by measurements. 
There are many cases, however, in which measurements are limited in their usefulness. There was some difficulty in obtaining in-phantom measurements at the accelerator facility used in this study because of the low count rate. A computer calculation is not limited by count rate, so it would be useful in characterizing fields too weak to measure. The neutron sources available for this study were limited by those that could be physically constructed, but there is no such limitation on computer modeling. A computer model can use any energy for an incident monoenergetic beam, whereas only a few are reasonably available, and the computer model could easily switch from a beam to a point source or an isotropic field, where none would be physically available.

Since arbitrary neutron sources can be easily modeled, calculations have been the primary tool for investigating effects inside the body resulting from external sources of radiation. A complete set of fluence-to-dose conversion factors is assembled from a number of calculations using different monoenergetic neutron sources, so many calculations are performed to produce the data set.

This study had a self-imposed limitation of using a homogeneous plastic cylindrical phantom, primarily because of experimental considerations. It would be difficult to construct a more realistic phantom and measure doses using TEPCs because the detector placement must displace some material, and the dose measured by a detector is applicable only to a small region. If a realistic phantom representing a human torso were employed, it would be difficult to measure the dose that would be applicable to an entire organ.

In the past, calculations to determine fluence-to-dose and fluenceto-dose-equivalent conversion factors have used the same simplification of a homogeneous phantom with a simple geometrical shape, such as a sphere or cylinder, to approximate a phantom. It is quite understandable that such a simplification would have been used 20 years ago when computer hardware and software were more primitive than those currently available. With the availability of supercomputers and transport codes such as MCNP, however, there is no need to make extreme simplifications in modeling the human torso. Therefore, it is surprising to see the reconmendation in ICRU 39 of using a 
spherical phantom for dose calculations that are the basis for evaluating dose equivalents from external radiation (ICRU 1986).

Instead of using a simple geometrical shape for a phantom to approximate the human torso, it would be much more accurate to use an anthropomorphic phantom. Several mathematical models exist for defining the internal organs in terms of mathematical equations that can be used in a computer code. This type of anthropomorphic phantom would enable the calculation of doses to internal organs, and the corresponding dose equivalents could be weighted by critical organ-weighting factors, as recomended in ICRP 26 (ICRP 1977), and summed to give effective dose equivalents. A series of these calculations for different incident neutron energies and source geometries would be a much more accurate basis for radiation protection than data sets based on simple cylindrical or spherical phantoms.

With the proposed changes in the ways that neutron dose equivalents are determined, it is likely that new sets of fluence-to-dose-equivalent conversion factors will be calculated and widely used. The results of this study should give a good degree of confidence that the calculations performed to derive these data sets give accurate and meaningful results. The study also gives a good indication that the TEPC detector is a useful tool for measuring doses from neutron radiation. 


\subsection{REFERENCES}

Auxier, J. A., W. S. Snyder, and T. D. Jones. 1968. "Neutron Interactions and Penetrations in Tissue." In Radiation Dosimetry, Vol. 1, 2nd ed. F. H. Attix and W. E. Roesch, eds. Academic Press, New York.

Cummings, F. M. 1984. TACI - A Code for Interactive Analys is of Neutron Data Produced by a Tissue Equivalent Proportional Counter. PKL-5136, Pacific Northwest Laboratory, Richland, Washington.

Caswell, R. S., and J. J. Coyne, 1980. Radiation Research 83, 217-254, Academic Press, New York.

DePangher, J., and L. L. Nichols. 1966. A Precision Long Counter for Measuring Fast Neutron Flux Density. BNWL-260, Pacific Northwest Laboratory, Richland, Washington.

International Comnission on Radiological Protection (ICRP). 1977. Radiation Protection. ICRP Publication 26, Pergamon Press, 0xford.

International Commission on Radiation Units and Measurements (ICRU). 1977. Neutron Dosimetry for Biology and Medicine. ICRU Report 26, Washington, D.C.

International Commission on Radiation Units and Measurements (ICRU). 1985. Determination of Dose Equivalents Resulting from External Radiation Sources. ICRU Report 39, Bethesda, Maryland.

International Commission on Radiation Units and Measurements (1CRU). 1986. The Quality Factor in Radiation Protection. ICRU Report 40, Bethesda, Maryland.

McDonald, J. C., R. V. Griffith, P. Plato, and J. Miklos. 1983. Measurements of Gamma-Ray Oose from a Moderated 252Cf Source. NUREG/CR-2957, U.S. Nuclear Regulatory Comission, Washington, D.C.

National Council on Radiation Protection and Measurements (NCRP) , 1971. Protection Against Neutron Radiation. NCRP Report No. 38, Washington, D.C.

Radiation Shielding Information Center (RSIC). 1983. MCNP, A Monte Carlo Neutron and Photon Transport Code. CCC-200, Los Alamos National Laboratory, Los Alamos, New Mexico.

Schaeffer, N. M., ed. 1973. Reactor Shielding for Nuclear Engineers. TI0-25951, U.S. Atomic Energy Commission, Washington, D.C.

Schwartz, R. B., and C. M. Eisenhauer. 1982. Procedures for Calibrating Neutron Personnel Dosimeters. NBS Special Publication 633, National Bureau of Standards, Washington, D.C. 
Stoddard, D. H. 1965. Radiation Properties of Californium-252. DP-986, E. I. duPont De Nemours \& Company, Savannah River Laboratory, Aiken, South Carolina. 
PNL -6913

UC-407

\section{DISTRIBUTION}

No. of

Copies

OFFSITE

10 DOE/Office of Scientific and Technical Information

DOE Headquarters

E. C. Baynard, III, Ass istant Secretary for Environment, Safety, and Health, EH-1 U.S. Department of Energy Washington, DC 20545

E. Blackwood Office of Safety Compliance, EH-34

U.S. Department of Energy Washington, DC 20545

10 K. P. Ferlic Division of Operational Standards and Analys is U.S. Department of Energy Washington, DC 20545

J. E. Fitzgerald, Jr., Director Office of Safety Policy and Standards, EH-35

U.S. Department of Energy Washington, DC 20545

R. W. Starostecki, Deputy Ass istant Secretary for Safety, Health, and Quality As surance, EH-30

U.S. Department of Energy Washington, DC 20545
No. of

Copies

F. E. Tooper, Acting Director

Division of Operational Standards and Analysis, EH-352

U.S. Department of Energy

Washington, DC 20585

DOE Albuquerque Operations

office

R. E. Alexander

Pantex Plant

Mason \& Hanger--Silas Mason Co., Inc.

P.0. Box 30020

Amarillo, TX 79177

W. D. Burnett

DOE Sandia National Laboratories Mail Code 3312, Bldg. 8619

P.0. Box 2800

Albuquerque, NM 87115

J. W. Doty

Mound Laboratory

Monsanto Research Corporation

Miamisburg, OH 45342

R. J. Erfurdt

Rockwell lnternational

Rocky Flats Plant

P.0. Box 464

Golden, $C 0 \quad 80401$

J. Puckett

Los Alamos National

Laboratory, K491

P.0. Box 1663

Los Alamos, NM 87545 
G. Runkle

U.S. Department of Energy

Albuquerque Operations office

P.0. Box 5400

Albuquerque, NM 87115

R. G. Stafford

Los Al amos Mational

Laboratory

P.0. Box 1663

Los Alamos, NM 87545

DOE Chicago Operations Office

L. V. Coulson

Fermi National Accelerator Laboratory

P.0. Box 500

Batavia, IL 60510

C. B. Meinhold

Brookhaven National Laboratory

Associated Universities, Inc. Upton, NY 11973

DOE Idaho Operations Office

F. M. Cunmings

U.S. Department of Energy

Idaho Operations office

785 DOE Place

1daho Falls, ID 83402

B. L. Rich

EG\&G Idaho

P.0. Box 1625

Idaho Falls, ID 83401

A. N. Tschaeche

WINCO

M/S CPP -630

P.0. Box 4000

Idaho Falls, ID 83403
DOE Nevada Operations Office

A. E. Bicker

Reynolds Electrical \& Engineering $\mathrm{Co}$., Inc.

P.0. Box 14400

Las Vegas, NV 89114

DOE Oak Ridge Operations

Office

R. J. Cloutier

Oak Ridge Associated

Universities

P.D. Box 117

Oak Ridge, TN 37831

R. E. Halliburton

Oak Ridge Nationai Laboratory P.0. Box $X$

Oak Ridge, TN 38730

S. L. Hinnefeld

Westinghouse Materials Co. of Ohio

P.0. Box 398704

Cincinnati, OH 45239

D. B. Howard

U.S. Department of Energy

Oak Ridge Operations office

P.0. Box E

Oak Ridge, TN 37831

G. D. Kerr

Oak Ridge National Laboratory

P.0. BOX Y, HASRO Bldg 7509

Oak Ridge, TN 37830

W. T. Mee

$\mathrm{Y}-12$

P.0. Box $Y$

Oak Ridge, TN 37830 
No. of

Copies

D. C. Parzyck

Oak Ridge National Laboratory P.0. Box $X$

Oak Ridge, TN 37830

S. F. Seltzer

Paducah Gaseous Diffusion Plant

P.0. Box 1410

Paducah, KY 42001

F. G. VanLoocke

RMI Company

P.0. Box 579

Ashtabula, OH 44004

E. R. Hagner

Portsmouth Gaseous Diffusion Plant

Mart in Marietta Energy Systems

P.0. Box 628

Piketon, OH 45661

H. D. Whitehead

Oak Ridge Gaseous Diffusion Plant

P. 0. Box 2003

Oak Ridge, TN 37831-7403

DOE San Francisco Operations Office

G. W. Campbell

Lawrence Livermore National Laboratory

P.0. Box 55D5

Livermore, CA 94550

T. R. Crites

Lawrence Livermore National Laboratory

P.0. Box 5505

Livermore, CA 94550
No. of

Copies

J. T. Davis

U.S. Department of Energy

San Francisco Operations Office

1333 Broadway

Oakland, CA 94612

D. E. Hankins

Lawrence Livermore National Laboratory

P.0. Box 5505

Livermore, CA 94550

R. C. McCall

Stanford Linear Accelerator

P.0. Box 4349

Stanford, CA 94305

R. H. Thomas

DOE Lawrence Berkeley

National Laboratory

Occupational Health Division, Bldg. 90/1106

Berkeley, CA 94720

G. Warren

Stanford Linear Accelerator Center

P.0. Box 4349

Stanford, CA 94305

DOE Savannah River Operations office

D. N. Bridges

U.S. Department of Energy

Savannah River Operations office

P.0. Box A

Aiken, SC 29801

K. Crase

E. I. duPont deNemours \& Co.

Savannah River Operations office

Aiken, SC 29801 
No. of

Copies

W. C. Reinig

E. I. duPont de Nemours \& Co.

Savannah River Plant

Aiken, SC 29809

EPA Office of Radiation

Programs

A. Richardson

401 M Street, SW

Washington, DC 20460

National Center for Devices

and Radiological Health

J. C. Villforth

FDA Bureau of Radiological Health

Rockville, MO 20852

National Institute of

Standards and Technology

R. S. Caswell

Chief, Ionizing Radiation Division

National Institute of

Standards and Technology

Gaithersburg, MD 20899

E. H. Eisenhower

National Institute of

Standards and Technology

Gaithersburg, HD 20899

R. B. Schwartz

National lnstitute of

Standards and Technology

Gaithersburg, MD $2089 \mathrm{~g}$

Nuclear Regulatory Commission

A. K. Roecklein

U.S. Nuclear Regulatory

Conmission, MS NL007

5620 Nicholson Lane

Rockville, MO 20555
No. of

Copies

OTHER
A. S. Bunker

The Techrite Company

4698 Kimball Ave. SE

Kentwood, MI 29508

L. A. Sigalla

45595 th Ave. N.E.

Seattle, WA 98105

R. E. Yoder

Science Applications

International Corporation 20030 Century Blvd.

Suite 201

Germantown, MD 20874

ONSITE

3 DOE Richland Operations

Office

E. C. Norman

54 Pacific Northwest Laboratory

W. J. Bair

L. W. Brackenbush

J. S. Durham

G.W.R. Endres

L. G. Faust (3)

D. E. Hadlock

J. R. Johnson

L. H. Munson

M. A. Parkhurst

W. D. Reece

R. 1. Scherpelz (30)

J. M. Selby

K. L. Soldat

C. M. Stroud

J. E. Tanner

J. R. Weber

Health Physics Department

Library

Publishing Coordination

Technical Report Files (5) 